Article

\title{
Whole Genome DNA Methylation Profiling of D2 Medium Spiny Neurons in Mouse Nucleus Accumbens Using Two Independent Library Preparation Methods
}

\author{
Yuxiang Li, Haiyang Xu, Javed M. Chitaman and Jian Feng * \\ Department of Biological Science, Program in Neuroscience, Florida State University, Tallahassee, FL 32306, USA; \\ yli@bio.fsu.edu (Y.L.); hxu@bio.fsu.edu (H.X.); jchitaman@neuro.fsu.edu (J.M.C.) \\ * Correspondence: feng@bio.fsu.edu; Tel.: +1-850-644-3706
}

check for updates

Citation: Li, Y.; Xu, H.; Chitaman, J.M.; Feng, J. Whole Genome DNA Methylation Profiling of D2 Medium Spiny Neurons in Mouse Nucleus Accumbens Using Two Independent Library Preparation Methods. Genes 2022, 13, 306. https://doi.org/ 10.3390 /genes 13020306

Academic Editor:

Subramaniam Jayanthi

Received: 24 December 2021

Accepted: 2 February 2022

Published: 6 February 2022

Publisher's Note: MDPI stays neutral with regard to jurisdictional claims in published maps and institutional affiliations.

Copyright: (c) 2022 by the authors. Licensee MDPI, Basel, Switzerland. This article is an open access article distributed under the terms and conditions of the Creative Commons Attribution (CC BY) license (https:/ / creativecommons.org/licenses/by/ $4.0 /)$.

\begin{abstract}
DNA methylation plays essential roles in various cellular processes. Next-generation sequencing has enabled us to study the functional implication of DNA methylation across the whole genome. However, this approach usually requires a substantial amount of genomic DNA, which limits its application to defined cell types within a discrete brain region. Here, we applied two separate protocols, Accel-NGS Methyl-Seq (AM-seq) and Enzymatic Methyl-seq (EM-seq), to profile the methylome of D2 dopamine receptor-expressing medium spiny neurons (D2-MSNs) in mouse nucleus accumbens (NAc). Using 40 ng DNA extracted from FACS-isolated D2-MSNs, we found that both methods yielded comparably high-quality methylome data. Additionally, we identified numerous unmethylated regions (UMRs) as cell type-specific regulatory regions. By comparing the NAc D2-MSN methylome with the published methylomes of mouse prefrontal cortex excitatory neurons and neural progenitor cells (NPCs), we identified numerous differentially methylated $\mathrm{CpG}$ and non-CpG regions. Our study not only presents a comparison of these two low-input DNA whole genome methylation profiling protocols, but also provides a resource of DNA methylome of mouse accumbal D2-MSNs, a neuron type that has critical roles in addiction and other neuropsychiatric disorders.
\end{abstract}

Keywords: DNA methylation; methylome; DRD2; medium spiny neuron; nucleus accumbens; mouse

\section{Introduction}

DNA methylation is an epigenetic mechanism that plays important roles in gene regulation and genome stability [1]. In mammals, DNA cytosine methylation is vital for development and cell fate commitment, cell identity maintenance, and various other cellular functions [2-9]. DNA cytosine methylation is deposited by a group of DNA methyltransferase enzymes (DNMTs) [10] and can be oxidized by ten-eleven translocation (TET) methylcytosine dioxygenases that may lead to DNA demethylation [6,11].

To study DNA methylation, several methodologies have been developed. For example, methylation-sensitive restriction enzymes are used to infer the methylation status of genomic loci based on their differential enzymatic cutting activity at DNA motifs containing methylated or unmethylated cytosines [12]. In contrast, antibodies against methylated cytosines have also been developed to examine methylation status by immunostaining or by immunoprecipitation followed by sequencing $[8,13,14]$. Additionally, sodium bisulfitebased techniques can be used to differentiate methylated and unmethylated states of DNA, as sodium bisulfite deaminates unmethylated cytosines into uracils while leaving methylated ones intact $[15,16]$. Combining bisulfite treatment and next-generation sequencing, therefore, allows for DNA methylation profiling across the entire genome with single-base resolution and in a quantitative manner [17-21].

With the advent of methylome profiling techniques, the spatiotemporal dynamics of DNA methylation during embryogenesis and development have been revealed to usually 
exist in cell type-specific patterns [22-26]. Accumulating evidence also implicates the role of DNA methylation in brain functions as well as in brain disorders, such as drug addiction [27-31]. Nucleus accumbens (NAc) is a key structure of the ventral striatum that plays a critical role in adaptive, goal-directed behaviors and mediates the seeking and using of addictive drugs [32,33]. In NAc, over $95 \%$ of neuronal cells are GABAergic medium spiny neurons (MSNs), which are further classified as D1 dopamine receptor-expressing MSNs (D1-MSNs) and D2 dopamine receptor-expressing MSNs (D2-MSNs) [34,35]. Furthermore, NAc D1-MSNs and D2-MSNs belong to separate circuitries that have distinct roles in drug-induced behavioral responses, whereby stimulation of D1-MSNs promotes reward and motivational behaviors, while activation of D2-MSNs inhibits these behaviors. Due to the heterogeneity of neuronal populations within NAc, it is of interest to profile the accumbal DNA methylome in a neuronal subtype-specific manner.

A major challenge to study the DNA methylome of neuronal subtypes from discrete brain regions is the limited yield of genomic DNA that can be retrieved from these cells, which is usually below the range of conventional whole-genome methylome profiling protocols. To address this, several innovative variations of these protocols have been developed, such as tagmentation-based whole-genome bisulfite sequencing [36], post-bisulfite adaptor tagging (PBAT) [25,37-39], and other methods using DNA modification enzymatic conversion [40-42]. Unlike traditional sequencing library preparations, in which substantial sample loss occurs at multiple library preparation steps, tagmentation-based methods (e.g., Tn5mC-seq) utilize a Tn5 transposase derivative to fragment DNA and append adaptors in a single step to increase library preparation efficiency. Therefore, Tn $5 \mathrm{mC}$-seq can be used to generate high-quality bisulfite sequencing libraries from low-input (1-10 ng) genomic DNA [36]. However, it may have potential biases due to the preference of transposase, and substantial DNA damage owing to bisulfite treatment. Traditionally, whole-genome bisulfite sequencing requires larger quantities (microgram) of DNA. This is mainly because sequencing adaptors are ligated to DNA fragments before bisulfite treatment, which results in a significant DNA template loss after bisulfite conversion. To overcome this limitation, post-bisulfite library preparation (e.g., PBAT) takes an alternative approach to prepare DNA adaptor tagging after bisulfite treatment [37]. It also incorporates random priming with biotin-labeled primers followed by enrichment of biotinylated fragments to circumvent a potential amplification failure due to bisulfite treatment-induced DNA break. However, this highly efficient low-input protocol still relies on the recovery rate of bisulfite-treated DNA and has shown GC content-related biases associated with random priming amplifications. Lately, methods based on an enzymatic conversion of methylated DNA, which do not include any bisulfite treatment, have been used to bypass the associated bisulfite-induced DNA degradation, and promise better DNA recovery than bisulfite-based approaches [40-42]. For example, TET-assisted pyridine borane sequencing (TAPS) adapts sequential pyridine borane reduction followed by TET1 oxidation of methylated cytosine to detect cytosine methylation of samples as little as $10 \mathrm{ng}$ DNA. While these approaches have been successfully applied for low-input DNA samples in various studies, comparisons of performance and potential biases of such methods in low-abundance neuronal samples remain limited.

Here, we generated the methylome of D2-MSNs from NAc of male mice using two independent library preparation methods. The preparation was achieved through two distinct strategies from separate commercial kits: the sodium bisulfite-based Accel-NGS Methyl-Seq (AM-seq) of Swift biosciences (Cat\# 30024) and the enzymatic conversion-based method Enzymatic Methyl-seq (EM-seq) from New England Biolabs (Cat\# E7120S). AM-seq takes advantage of a proprietary adaptase to effectively capture single-stranded DNA and may improve library preparation efficiency after sodium bisulfite treatment of DNA. In contrast, EM-seq potentially improves the metrics of methylation profiling by substituting bisulfite treatment with enzymatic reactions; TET2 and $\beta$-glucosyltransferase are used to catalyze the conversion of methylated cytosine, followed by apolipoprotein B mRNA 
editing enzyme catalytic subunit 3A (APOBEC3A)-mediated deamination of unmethylated cytosines [42].

We applied fluorescence-activated cell sorting (FACS) to isolate D2-MSNs from NAc of Drd2a-eGFP (D2-eGFP) mice, in which D2-MSNs are labelled with eGFP [43]. Using 40 ng DNA available from NAc D2-MSNs of a single mouse brain, we were able to generate high-quality whole-genome methylome data using either of the two aforementioned methods. Therefore, our study not only provides valuable technical evaluations of the current methods available for low cell number whole genome methylome profiling, but also generates a reference methylome dataset of NAc D2-MSNs, which play important roles in addiction and various other neuropsychiatric disorders.

\section{Materials and Methods}

\subsection{Animal, D2-MSN Isolation, and DNA Extraction}

Male D2-eGFP mice [43] were born and raised in a controlled laboratory environment under a $12 \mathrm{~h}$ reverse light/dark lighting cycle at $22-25^{\circ} \mathrm{C}$. Pups were weaned at postnatal day 21 and were group-housed alongside up to 4 mice per cage with ad libitum access to food and water. All mice used in this study were of a C56BL/6J genetic background. All experiments followed the guidelines of the Animal Care and Use Committee of Florida State University.

Mouse brains were immediately removed after cervical dislocation and decapitation, and then sectioned in a stainless-steel brain matrix ( $1 \mathrm{~mm}$ intervals) on ice. Four micropunches of NAc were collected from each brain by a 14-gauge blunt-tip needle and minced into small pieces in ice-cold Hibernate A minus calcium medium (Brainbits, \#HACA500, Springfield, IL, USA) plus B27 supplement (Fisher scientific, \#17504044, Waltham, MA, USA). The minced tissue was then incubated in Hibernate A minus calcium medium with $20 \mathrm{unit} / \mathrm{mL}$ papain (Worthington, \#LK003176, Lakewood, NJ, USA), 5\% trehalose (Acros organics, \#AC30987, Geel, Belgium), and $0.1 \mathrm{mg} / \mathrm{mL}$ DNase (Worthington, \#LK003170, Lakewood, NJ, USA) at $37^{\circ} \mathrm{C}$ for $30 \mathrm{~min}$ with $700 \mathrm{rpm}$ agitation. After being washed by Hibernate A minus calcium medium with $1 \%$ BSA, the tissue was triturated to cell suspension. After passing through a $70 \mu \mathrm{m}$ cell strainer, the cell suspension was sorted on a FACS Aria SORP (BD, San Jose, CA, USA) using a $100 \mu \mathrm{M}$ nozzle, and the GFP-positive D2-MSNs were collected in ice-cold $1 \times$ PBS buffer with $1 \%$ BSA. To isolate D2-MSNs by FACS, all cells were initially gated on SSC-A vs. FSC-A plot ('P1' gate). GFP positive cells represented $4-5 \%$ of the parent population (Figure S1a). Next, we derived gate 'P6' by plotting SSC-H vs. FSC-H, which was then used to discriminate GFP positive cells from negative cells. The GFP-positive population was increased to $9.9-12.7 \%$, or more than 2 -fold higher when plotted by just SSC-A and FSC-A. Within each sample, the P6 gating was compared to P1 gating and adjusted to match the GFP positive cell number. In total, 12k-22k GFP-positive cells were collected as D2-MSNs from each mouse brain. Using real-time PCR, we confirmed that the GFP-positive population we collected expressed high levels of a D2-MSN marker gene rather than D1-MSN marker genes (Figure S1b).

Genomic DNA was extracted with the AllPrep DNA/RNA Micro Kit (Qiagen, \#80284, Hilden, Nordrhein-Westfalen, Germany) by following the product manual. Briefly, sorted cells were pelleted by $500 \times g$ centrifugation for $5 \mathrm{~min}$, and the supernatant was carefully removed. Next, $350 \mu \mathrm{L}$ RLT Plus buffer with 2-Mercaptoethanol added was used to release genomic DNA, which was subsequently enriched on supplied binding columns. The columns were washed with $500 \mu \mathrm{L}$ buffer AW1, followed by $13,000 \times g$ centrifugation for $1 \mathrm{~min}$. After another round of washing with $500 \mu \mathrm{L}$ buffer AW2 and 13,000 $\times g$ centrifugation for $1 \mathrm{~min}$, the flow-through was removed, and the column was centrifuged at $13,000 \times \mathrm{g}$ for another $2 \mathrm{~min}$. DNA was then eluted into $30 \mu \mathrm{L}$ elution buffer. In this study, three adult male mice were used: one was 96 days old and used as replicate 1 (Rep1); the other two were 97 days old and combined as replicate 2 (Rep2). 


\section{2. $q P C R$}

Four NAc micropunches each from three untreated D2-eGFP adult male mice were used to verify the identity of FACS-isolated cells. For each sample, GFP-positive cells identified by FACS were sorted into $1 \mathrm{~mL}$ ice-cold TRIzol Reagent (Invitrogen, \#15596026, Waltham, MA, USA), and total RNA was extracted according to manufacturer's instructions. Briefly, cells were lysed in TRIzol Reagent, and cellular contents were separated into phases by vigorously mixing with chloroform and centrifuging. RNA was then precipitated by transferring the aqueous phase into absolute ethanol, pelleted by centrifugation, and washed with $75 \%$ ethanol. Following the final ethanol wash, RNA pellets were air-dried and resuspended in nuclease-free water. Total RNA from GFP-positive cells was reversetranscribed into cDNA using qScript cDNA SuperMix (Quantabio, \#95048025, Beverly, MA, USA). cDNA and target gene primers were mixed with PerfeCTa SYBR Green SuperMix (Quantabio, \#95056500, Beverly, MA, USA) according to the manufacturer's instructions, and target gene expression was quantified by qPCR using a 7500 Fast Real-Time PCR System (Applied Biosystems, \#4351107, Waltham, MA, USA ). For every gene target, three biological replicates with two technical replicates each were used for quantification. Average target gene expression was normalized to average Gapdh expression within each sample.

The primers are as follows. Gapdh F: GGGTGTGAACCACGAGAAAT, Gapdh R: GTCTTCTGGGTGGCAGTGAT; Drd1 F: GTCTCCCAGATCGGGCATT, Drd1 R: AGTCACTTTTCGGGGATGCT; Pdyn F: TGAATCTTGGATCGGCCACC, Pdyn R: CCACGCAGATCTCAAAGCCT; Zfp521 F: GGGCCTTGCTTCCATTTTCC, Zfp521 R: TTGAGGGATCTCGGTTTCGC; Drd2 F: ATCTCTTGCCCACTGCTCTTTGGA, Drd2 R: ATAGACCAGCAGGGTGACGATGAA.

\subsection{Sequencing Library Preparation}

Each of the two biological replicates (Rep1, Rep2) were split into two 40 ng genomic DNA aliquots for AM-seq and EM-seq library preparation, respectively. For AM-seq preparation, we used the Accel-NGS Methyl-Seq DNA Library Kit (Swift, \#30024, Ann Arbor, MI, USA) by following kit instructions. For EM-seq preparation, we applied the NEBNext Enzymatic Methyl-seq Kit (NEB, \#E7120S, Ipswich, MA, USA) by following the product manual. Therefore, for each of the two biological replicates (Rep1, Rep2), one AM-seq and one EM-seq libraries were prepared.

For AM-seq library preparation, 40 ng D2-MSN DNA with 4 pg unmethylated lambda DNA (Promega, \#D1521, Madison, WI, USA) and 4 pg CpG methylated puc19 DNA (NEB, \#E7120S, Ipswich, MA, USA) as spike-in controls were fragmented to an average size of 350 bp using Covaris E220 (Covaris, Woburn, MA, USA) (60s duration, 30 peak power, 20\% duty factor, 50 cycles/burst, average power 6), followed by bisulfite treatment with EZ DNA Methylation-Gold Kits (Zymo, \#D5005, Irvine, CA, USA) per the provided instruction. The $20 \mathrm{ul}$ fragmented DNA went through conversion with $130 \mu \mathrm{L}$ CT Conversion Reagent by incubating for $10 \mathrm{~min}$ at $98{ }^{\circ} \mathrm{C}$ followed by $2.5 \mathrm{~h}$ at $64{ }^{\circ} \mathrm{C}$. Each converted sample was mixed with $600 \mu \mathrm{L}$ M-Binding buffer, loaded into an IC column, and centrifuged at $13,000 \times g$ for $30 \mathrm{~s}$. Each column was then washed with $100 \mu \mathrm{L}$ M-Wash buffer, followed by $13,000 \times g$ centrifugation for $30 \mathrm{~s}$. Next, $200 \mu \mathrm{L}$ of M-Desulphonation buffer was added to the column and incubated at room temperature for $15 \mathrm{~min}$. After desulphonation, each column was centrifuged at $13,000 \times g$ for $30 \mathrm{~s}$, washed with $200 \mu \mathrm{L}$ M-Wash buffer twice, then $15 \mu \mathrm{L}$ M-Elution buffer was applied to elute DNA. The resultant converted DNA was used for library preparation with the Accel-NGS Methyl-Seq DNA Library kit by following the manufacturer's instructions. Briefly, $15 \mu \mathrm{L}$ converted DNA was denatured for $2 \mathrm{~min}$ at $95{ }^{\circ} \mathrm{C}$ and then placed on ice for $2 \mathrm{~min}$. Then, $25 \mu \mathrm{L}$ Adaptase mix was added to the denatured DNA and incubated for $15 \mathrm{~min}$ at $37^{\circ} \mathrm{C}$, followed by $2 \mathrm{~min}$ at $95^{\circ} \mathrm{C}$. Next, $44 \mu \mathrm{L}$ of extension reaction mix was added, and the extension reaction was carried out in a thermocycler with an extension program of $98^{\circ} \mathrm{C}$ for $1 \mathrm{~min}, 62^{\circ} \mathrm{C}$ for $2 \mathrm{~min}, 65^{\circ} \mathrm{C}$ for $5 \mathrm{~min}$, and held at $4{ }^{\circ} \mathrm{C}$. The DNA was cleaned up with $1.2 \times$ volume of SPRIselect magnetic beads (Beckman Coulter, \#B23317, Indianapolis, IN, USA) and reclaimed with $15 \mu \mathrm{L}$ elution buffer. 
The ligation was then performed by adding $15 \mu \mathrm{L}$ ligation mix followed by a purification step with $1 \times$ volume of magnetic beads. The purified DNA was then used for 7 cycles of indexing PCR with indexed primers. Finally, the amplified library was purified by using $0.85 \times$ volume of magnetic beads.

For EM-seq library preparation, 40 ng D2-MSN DNA with 4 pg unmethylated lambda DNA (Promega \#D1521, Madison, WI, USA) and 4 pg CpG methylated puc19 DNA (NEB, \#E7120S, Ipswich, MA, USA) as spike-in was fragmented to an average size of $270 \mathrm{bp}$ using Covaris E220 (Covaris, Woburn, MA, USA) (120 s duration, 50 peak power, 25\% duty factor, 1000 cycles/burst, avg power 12.5). The library was then prepared using the NEBNext Enzymatic Methyl-seq kit per the manufacturer's instructions. For each sample, $50 \mu \mathrm{L}$ fragmented DNA was repaired with $10 \mu \mathrm{L}$ End Prep Mix at $20^{\circ} \mathrm{C}$ for $30 \mathrm{~min}$ and followed by incubation at $65^{\circ} \mathrm{C}$ for $30 \mathrm{~min}$. Repaired DNA was ligated with methylated adaptors, purified with $110 \mu \mathrm{L}$ magnetic beads and reclaimed with $28 \mu \mathrm{L}$ elution buffer. The $28 \mu \mathrm{L}$ purified DNA was used for methylcytosine oxidation with $17 \mu \mathrm{L}$ TET2 reaction mix and $5 \mu \mathrm{L} \mathrm{Fe}(\mathrm{II})$ solution. After $1 \mathrm{~h}$ of TET2 oxidation at $37^{\circ} \mathrm{C}$, the reaction tube was placed on ice, $1 \mu \mathrm{L}$ of Stop Reagent was added, and samples were incubated at $37^{\circ} \mathrm{C}$ for $30 \mathrm{~min}$ to stop the oxidation reaction. The oxidated DNA was purified with $90 \mu \mathrm{L}$ magnetic beads and eluted in $16 \mu \mathrm{L}$ elution buffer. Then, $4 \mu \mathrm{L} 0.1 \mathrm{M} \mathrm{NaOH}$ was added to denature the purified oxidated DNA at $50^{\circ} \mathrm{C}$ for $10 \mathrm{~min}$, and the reaction tube was placed on ice after the denaturation. Deamination was immediately carried out by adding $80 \mu \mathrm{L}$ APOBEC reaction mix and incubated at $37^{\circ} \mathrm{C}$ for $3 \mathrm{~h}$. The converted DNA was purified with an equal volume of magnetic beads and reclaimed with $20 \mu \mathrm{L}$ elution buffer. Indexed primers were added to purified DNA for 5 cycles of amplification, and each amplified library was purified with $0.9 \times$ volume of magnetic beads.

The AM-seq and EM-seq libraries were assayed by a 4200 TapeStation system (Agilent, Santa Clara, CA, USA), and the molar concentrations were quantified by a KAPA library quantification kit (Roche \#07960336001, Basel, Switzerland). The libraries were then pooled with base-balanced libraries and sequenced for $100 \mathrm{bp}$ paired-end reads on Illumina Novaseq 6000 S1 flow cell with 30\% spike-in of whole-genome sequencing libraries. All libraries were sequenced twice and combined to reach the final read depths.

\subsection{AM-Seq and EM-Seq Data Analysis}

FASTQ files containing sequencing reads were checked by FastQC v0.11.9 (https: / /www.bioinformatics.babraham.ac.uk/projects/fastqc/, accessed on 31 January 2020). To remove low-quality sequences (Quality Phred score $<20$ ) and artificial adaptor sequences, Trim Galore 0.6.4 and Cutadapt 1.18 were used. Due to the synthetic adaptors generated during library preparation, we trimmed an additional $18 \mathrm{bp}$ from the $5^{\prime}$ end and $4 \mathrm{bp}$ from the $3^{\prime}$ end for both reads of AM-seq libraries. For both reads of EM-seq libraries, we trimmed $8 \mathrm{bp}$ from the $5^{\prime}$ end and $4 \mathrm{bp}$ from the $3^{\prime}$ end according to the positional base content bias result by FastQC. Read-pairs with any one read less than $20 \mathrm{bp}$ were removed. Processed read-pairs were aligned to the male mm10 mouse genome (https: / / www.encodeproject.org/files/male.mm10, accessed on 9 February 2019) by Bismark [44]. We performed alignment with the same processed reads as well as DNA reference sequence of lambda DNA or puc19 DNA to assess the conversion rate. After alignment, deduplication, and filtration of unconverted read pairs, methylation sites with genomic base coordinates and genomic context information were extracted by Bismark_methylation_extractor. Downstream analysis was performed with methylation sites separated according to their dinucleotide context (CG, CA, CT, CC).

\subsection{Bioinformatic Analysis of Methodology Comparison}

We used CollectGcBiasMetrics of Picard (http://broadinstitute.github.io/picard/, accessed on 18 August 2021) and QualiMap v.2.2.2-dev [45] to perform coverage analysis. For unconverted tetranucleotide bias analysis, the frequency of unconverted tetranucleotides was extracted by Bismark. For coverage deviation per dinucleotide analysis, 
4 million randomly sampled aligned read pairs ( $\sim 1 \%$ of total) were analyzed against randomly shuffled regions in the covered genomic region of the same library, and this analysis was repeated three times with different sampling seeds. All called methylation sites were used to calculate the global $\mathrm{CpG}$ and $\mathrm{CpH}$ methylation levels.

The genomic features of $\mathrm{CpG}$ islands were downloaded from the University of California at Santa Cruz (UCSC) Table Browser [46]. A list of putative mouse striatum enhancers was obtained from EnhancerAtlas 2.0 [47], and liftOver was applied to convert enhancer coordinate annotations in $\mathrm{mm} 9$ to $\mathrm{mm} 10$. Transcription starting sites (TSS) and other gene annotations were extracted from the Ensembl gene annotation system (Mus_musculus.GRCm38.90) [48]. The aggregated methylation profile was generated using BEDTools [49] and Deeptools [50]. To calculate methylated sites, we performed a binomial test as previously reported [51]. The non-conversion rate for each cytosine context was used to calculate the binomial $P$-value, and a threshold was chosen with false discovery rate (FDR) less than $1 \%$.

\subsection{Unmethylated Region Analysis}

The unmethylated regions (UMRs) were identified by MethylSeekR with recommended parameters (30 CpG sites, 50\% methylation level threshold) [52,53] using CpG methylation data after merging the four individual D2-MSN methylomes. The genomic annotation of UMR was performed by "annotatePeaks.pl" of Homer [54]. Histone ChIP-seq data was retrieved with the accession number GSE42810 and GSE63749 from the National Center for Biotechnology Information (NCBI) Sequence Read Archive (SRA). Motif enrichment was conducted by "findMotifsGenome.pl" of Homer. The genomic data files were transformed to bigWig format and visualized by IGV 2.8.6.06 [55]. The GO analysis of UMR regions was performed in $\mathrm{R}$ with the "clusterProfiler" package [56].

\subsection{Differential Methylation Region (DMR) Analysis}

The D2-MSN methylome was compared to the methylomes of mouse PFC CamKIIapositive (CamKIIa+) excitatory neurons (GSM1541958 and GSM1541959) [22] and neural progenitor cells (GSE111283) [57]. Methylome data of MethylC-seq were downloaded from NCBI. We filtered the common mouse SNP sites and removed sites with coverage less than 4. To perform differential methylation analysis for CpG methylation, DSS [58] with a smoothing function [59] was used to identify DMRs. The methylation change threshold was set as $20 \%$, and the $P$-value threshold was set as $1 \times 10^{-5}$ to focus on substantially changed regions. We merged DMRs within $500 \mathrm{bp}$ and set the length threshold for $\mathrm{CpG}$ DMR as $100 \mathrm{bp}$ with a minimum of $5 \mathrm{CpG}$ sites.

For non-CpG methylation, we chose to analyze methylated $\mathrm{CpA}$ dinucleotides (mCpA) as a representative [60]. In calculating $\mathrm{mCpA}$ levels of all genes, only the longest isoform of each gene was used. The methylation level of $1 \mathrm{~kb}$ windows with $500 \mathrm{bp}$ slide was used for differential $\mathrm{mCpA}$ analysis with DSS, the methylation change threshold was set as $2 \%$, and the $p$-value threshold as 0.01 . We merged mCpA DMRs within $50 \mathrm{~kb}$ and set the length threshold as $2 \mathrm{~kb}$. The web-based tool GREAT [61] was used to perform gene ontology analysis for DMR regions.

\section{Results}

\subsection{Whole Genome Methylome Library Preparation and Sequencing}

One AM-seq and one EM-seq libraries were generated from each of the two biological replicates (Rep1, Rep2) of mouse nucleus accumbens D2-MSNs. Similar amounts of DNA libraries were obtained from AM-seq (7 cycles of PCR library amplification) and EM-seq (5 cycles of PCR library amplification) (Table S1). Each library yielded around $400 \mathrm{M}$ paired-end reads (Table S1). Though all reads have consistently high quality, read 1 of all libraries is of notably better quality than read 2, with fewer base pairs removed during quality-trimming (Table S2). After adaptor trimming, quality trimming ( $\mathrm{q}>20)$, and read length filtering, over $99.6 \%$ of all reads passed quality thresholds. AM-seq has a slightly 
lower survival rate than EM-seq, mainly because AM-seq has more short reads ( $<20 \mathrm{bp}$ ) that were removed (Figure 1a, Table S2).

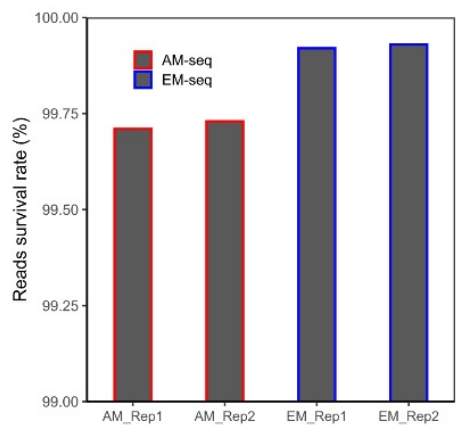

d

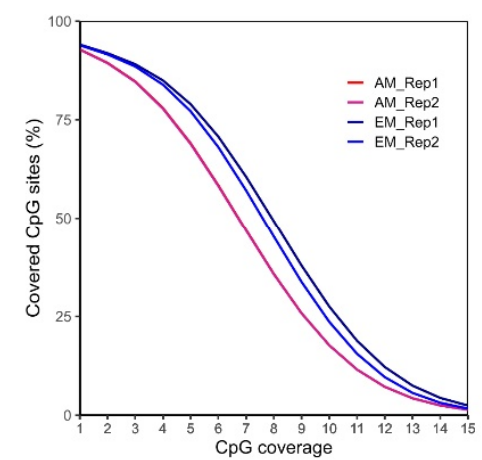

g

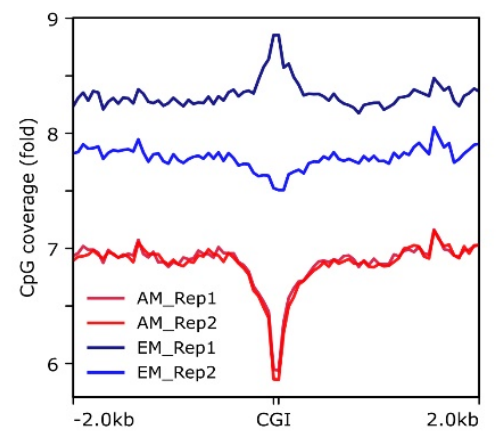

b

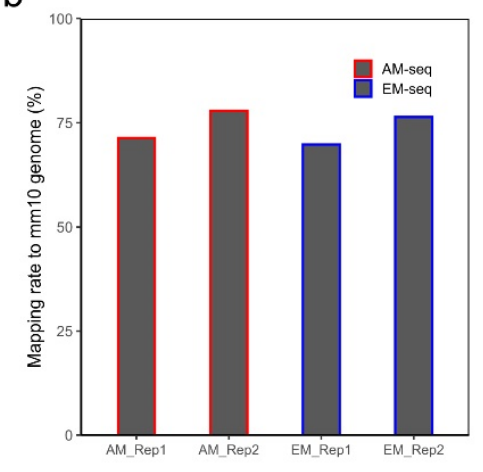

e

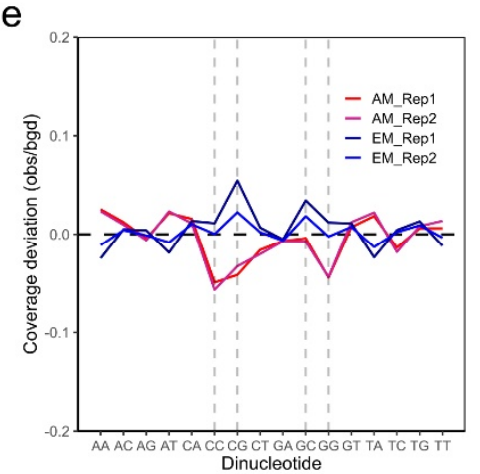

$\mathrm{h}$

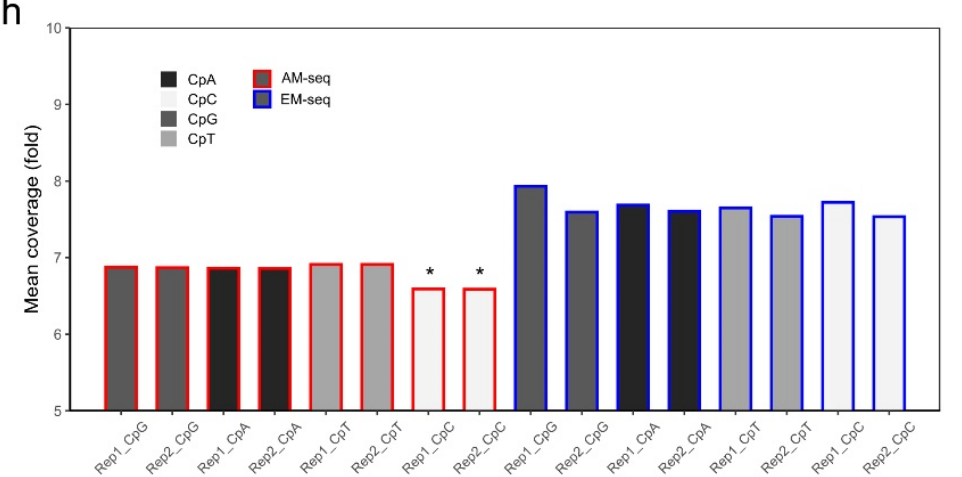

C

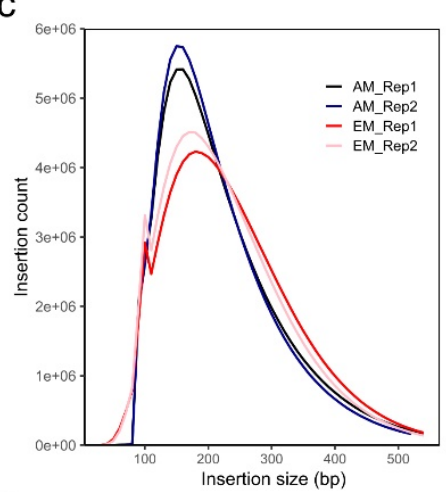

f

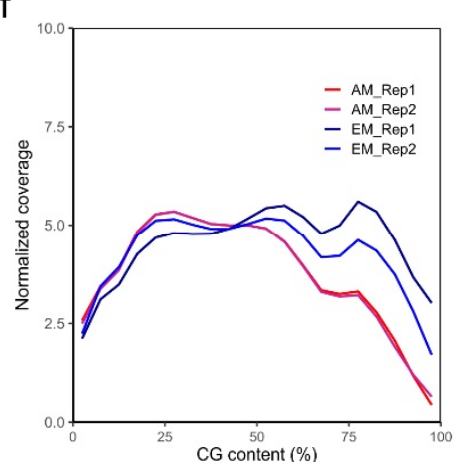

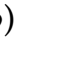


texts (Figure S2a). Furthermore, AM-seq libraries also had the highest non-conversion rates at $\mathrm{CpA}$ sites, whereas EM-seq had the lowest non-conversion rates at $\mathrm{CpA}$ sites (Figures S2a and S2b). Using CpG-methylated puc19 DNA as a conversion control, we found that AM-seq libraries had slightly higher over-conversion rates (3-4\%) compared to EM-seq (1-2\%) (Figure S2c).

Trimmed sequencing reads were then aligned to the male mouse mm10 reference genome, which revealed that the mapping ratio is more variable across biological replicates than library preparation methods (Figure 1b). In either AM-seq or EM-seq, Rep 2 had 6\% higher mapping ratio than Rep 1. For each sample, the AM-seq library had slightly higher $(\sim 1 \%)$ mapping ratios than that of its EM-seq library counterpart. The duplication rates of the four libraries were between $13.5 \%$ and $17.5 \%$ (Figure S2d), and the lower duplication rates in EM-seq indicate that the EM-seq libraries had better library complexity, given that they had the same sequencing depth as AM-seq but with two fewer PCR amplification cycles during library preparation. Consistent with this finding, when we extrapolated the library sizes using Preseq [62], we found the predicted unique fragments of the four libraries were between 1.4-1.6 billion, with better complexity and larger library sizes in EM-seq (Figure S2e).

AM-seq was previously reported to have an excellent genomic coverage [63]. By comparing AM-seq and EM-seq, we found both methods generated similar genome coverage across the whole genome (Figure S2f). We achieved over 15-fold genome coverage with $400 \mathrm{M}$ paired-end reads in each of the four libraries. Comparing the libraries derived from the same DNA, EM-seq yielded higher coverage compared to AM-seq. Part of the coverage difference may be attributed to the randomly added synthetic tail ( $15 \mathrm{bp}$ ) to $3^{\prime}$ ends of ssDNA during AM-seq library preparation, which required extra base pair sequence trimming before alignment. Another possible explanation is that EM-seq libraries had larger insert sizes as shown in sequencing (Figure 1c) or TapeStation analysis (Figure S2g), with AM-seq libraries shifted more toward the smaller size range, whereas EM-seq libraries had a more balanced size distribution.

We next extracted the methylated cytosine sites from the four libraries after balancing them to the same uniquely aligned reads by down-sampling. From an equal amount of uniquely aligned reads, similar coverage was observed between the two methods, with EM-seq having a slightly better performance. Out of the $\sim 43.7$ million CpG sites in the mouse genome (mm10), EM-seq covered more than 41 million (93.8\% of total CpG sites) CpG sites, compared to AM-seq at about 40.5 million (92.7\% of total CpG sites). EM-seq also had marginally better depth of CpG sites coverage than AM-seq (Figure 1d). Among them, the EM-seq Replicate 1 (EM_Rep1) library had the longest inserts (Figure 1c) and the highest $\mathrm{CpG}$ coverage after balancing aligned fragment counts.

Sodium bisulfite treatment, upon which the AM-seq protocol is based, has been known to cause DNA breaks and have biases at CG-rich regions during PCR amplification [21,64]. In comparison to the conventional whole genome bisulfite sequencing method, AM-seq was reported to perform better with respect to nucleotide amplification bias [63]. We found that both AM-seq and EM-seq have minuscule coverage deviations per dinucleotide context. However, compared to EM-seq, AM-seq had lower coverages at CpC, CpG, and GpG dinucleotides, possibly related to the bisulfite-induced DNA damage (Figure 1e). Notably, we found EM-seq had an over-representation at CpG and GpC dinucleotides, which indicates the bias might be an effect of high hydrogen bonding in CpG dinucleotides on PCR amplification, or of the TET2-mediated enzymatic conversion. We also noted a consistent trend that the genomic regions with higher CG content are less represented in AM-seq (Figure 1f). For example, at CpG islands (CGIs), which are genomic regulatory elements characterized by a high frequency of CpG sites and hypomethylation [65], AMseq had lower ( $14 \%$ less) coverage than at adjacent regions, whereas EM-seq lacked any such variation. Similarly, EM_Rep1 had an increased coverage around CGI regions, while EM_Rep2 showed a slight decrease (Figure 1g). The average coverage for single-stranded $\mathrm{CpN}$ sites is 6.6 and 6.9 folds for the two AM-seq libraries, respectively, and more than 
7.5 folds for the two EM-seq libraries (Figure 1h). We also noticed AM-seq had a slightly lower $\mathrm{CpC}$ coverage than $\mathrm{CpG}, \mathrm{CpA}$, and $\mathrm{CpT}$, which were more similar to each other (Figure 1h).

\subsection{Methylation Profiling of D2-MSNs}

Next, the global methylation levels were calculated after cytosine methylation site extractions. The four libraries had comparable global $\mathrm{CpG}$ methylation levels ranging from 80.3-81.2\% (Figure 2a). Both AM-seq and EM-seq detected a slightly higher CpG level in Rep 2 than in Rep 1 ( $0.16 \%$ higher by AM-seq and $0.88 \%$ higher by EM-seq). Furthermore, the methylation level measurements between the two methods were very close, with the CpG level of EM_Rep1 being 0.2\% lower than that of AM_Rep1, and the CpG level of EM_Rep2 being 0.3\% higher than AM_Rep2.
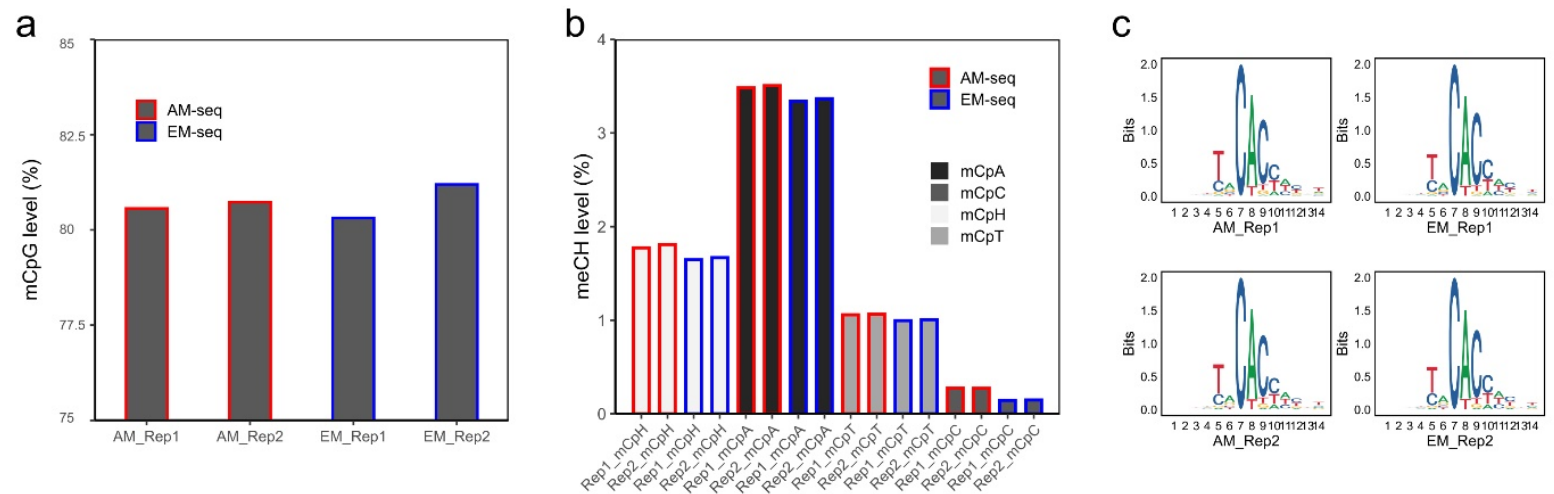

d

e
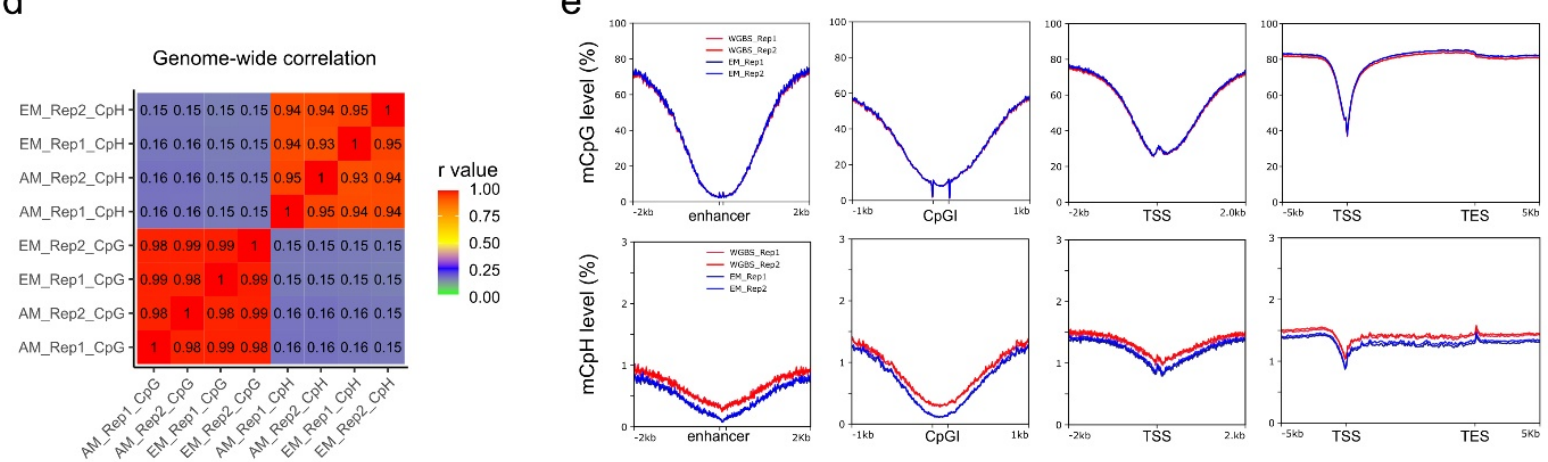

Figure 2. $\mathrm{CpG}$ and non-CpG methylation in NAc D2-MSNs. (a) Global CpG methylation levels calculated from AM-seq and EM-seq libraries. Y-axis starts from 75\%. (b) Non-CpG methylation levels. $\mathrm{mCpH}$ represents the (methylated $\mathrm{CpA}, \mathrm{CpT}$, and $\mathrm{CpC}$ )/(total $\mathrm{CpA}, \mathrm{CpT}$, and $\mathrm{CpC}$ ). (c) DNA motif of top hypermethylated non-CpG methylation sites. (d) Pearson correlation of $\mathrm{mCpG}$ and $\mathrm{mCpH}$ levels of the four methylome libraries using $10 \mathrm{~kb}$ bins. (e) Methylated CpG levels and methylated $\mathrm{CpH}$ levels at enhancers, CGIs, TSSs, and gene proximal regions using $50 \mathrm{bp}$ bins.

In addition, for non-CpG methylation, EM-seq demonstrated consistently lower methylation levels (Figure $2 \mathrm{~b})$ when compared to AM-seq. The methylated $\mathrm{CpH}(\mathrm{mCpH})$ levels (measurements of $\mathrm{mCpA}, \mathrm{mCpC}$, and $\mathrm{mCpT}$ together) were $1.77 \%$ and $1.8 \%$ in the two libraries of AM-seq and 1.65\% and 1.67\% in Rep1 and Rep2 of EM-seq, respectively. In D2-MSNs, similar to the previously reported non-CpG methylation distribution in neuronal methylomes [23], mCpA was found to be the predominant methylated non-CpG. Furthermore, we noted that, in both AM-seq and EM-seq datasets, $\mathrm{mCpG}$ accounted for 65-67\% of all cytosine methylation events, while $\mathrm{mCpA}$ and $\mathrm{mCpT}$ were responsible for $\sim 25 \%$ and $\sim 7 \%$, respectively. CpC had the lowest methylation frequency, which was $1.3-1.4 \%$ in AM-seq and $0.7-0.8 \%$ in EM-seq (Figure S3a). To identify high-confidence non-CpG methylation sites, we performed a binomial test with a false discovery rate method [23] and 
observed closer numbers of methylated CpG sites ( 52\%) and methylated non-CpG sites $(\sim 48 \%)$ in AM-seq, and slightly less methylated CpG sites (47\%) than methylated non-CpG sites (53\%) in EM-seq (Figure S3b).

Furthermore, the mCpA sites in D2-MSNs usually have an adjacent ' $\mathrm{T}$ ' upstream and a ' $\mathrm{CC}$ ' dinucleotide immediately downstream (Figure 2c). This sequence motif coincides with DNMT3A binding sites and is consistent with previous neuronal methylome reports [23,24, $51,66]$. Interestingly, the flanking sequences (5'-T and $\left.3^{\prime}-\mathrm{CC}\right)$ not only exist at mCpA sites, but also occur at $\mathrm{CpT}$, and $\mathrm{CpC}$ methylation sites (Figure S3c), which indicates a functional role of flanking DNA sequences at non-CpG methylation sites.

To examine the reproducibility of D2-MSN methylomes, we calculated the correlation of $10 \mathrm{~kb}$-binned $\mathrm{mCpG}$ and $\mathrm{mCpH}$ levels (Figure $2 \mathrm{~d}$ ). We found a strong correlation of $\mathrm{mCpG}$ methylation between the two D2-MSN replicates using either library preparation method. A significant correlation of $\mathrm{mCpH}$ methylation between the two biological replicates was also observed. Furthermore, we confirmed a strong correlation between methylomes generated by the two different methods (Figure 2d). As we observed subtle coverage bias between AM-seq and EM-seq according to GC content, we matched aggregated methylation levels of all four methylome libraries at various genomic regions (Figure 2e). We found that both $\mathrm{mCpG}$ and $\mathrm{mCpH}$ methylation are depleted at enhancers, CGIs, and transcription start sites (TSSs). Though the distribution patterns of CpG and $\mathrm{CpH}$ methylation in AM-seq and EM-seq were well-matched across these genomic features, we noticed that the $\mathrm{CpH}$ methylation levels of AM-seq libraries were slightly higher than that of EM-seq (Figure 2e). We then stratified $\mathrm{CpH}$ methylation to $\mathrm{mCpA}, \mathrm{mCpT}$, and $\mathrm{mCpC}$, and confirmed their consistent methylation patterns as well as relatively lower methylation levels in EM-seq (Figure S3d).

\subsection{D2-MSN Unmethylated Regions (UMRs)}

Using AM-seq and EM-seq, we profiled the D2-MSN methylome from the NAc of adult male mice. Given the high reproducibility of the four D2-MSN methylomes, we merged them to achieve a combined $~ 30$-fold coverage for each strand to identify D2MSN-specific regulatory regions. While the majority of the mammalian genome is highly methylated, a small portion of regions remains hypomethylated and are usually enriched with regulatory elements. Therefore, we focused on unmethylated regions (UMRs), which are long stretches of DNA segments with high CG frequency (i.e., more than $30 \mathrm{CpG}$ sites per region) and low DNA methylation levels (Figure S4a) that may have regulatory roles on transcription [51,52,67-70]. We found 15,310 UMRs (Table S4), with the majority of them located at regions close to transcription start sites, such as promoters, first introns, first exons, and 5' UTRs (Figure 3a). In addition, 12\% of UMRs were located in intergenic regions. In comparison to annotated mouse CGIs (UCSC Table Browser) and reported mouse striatal enhancers [47], the majority of UMRs (85\% of all UMRs) overlap with either $85 \%$ of CGIs or $89 \%$ of striatal enhancers (Figure $3 \mathrm{~b}$ ). The remaining $15 \%$ of UMRs that were not located at a CGI or enhancer may represent additional regulatory regions with low methylation levels in D2-MSNs. Furthermore, when compiled with the previously published mouse NAc histone modification ChIP-seq data [71], we found the UMRs were enriched with histone markers H3K4me1, H3K27ac, H3K4me3, and H3K27me3, which are usually associated with enhancers (H3K4me1, H3K27ac), active transcription initiation sites (H3K4me3), and repressive regulation ( $\mathrm{H} 3 \mathrm{k} 27 \mathrm{me} 3)$. In contrast, we found no enrichment of H3K36me3 or H3K9me2 at UMR regions (Figure 3c). 
a

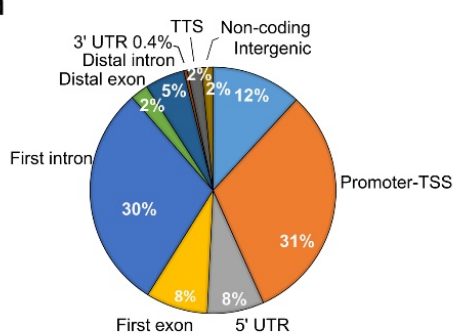

d

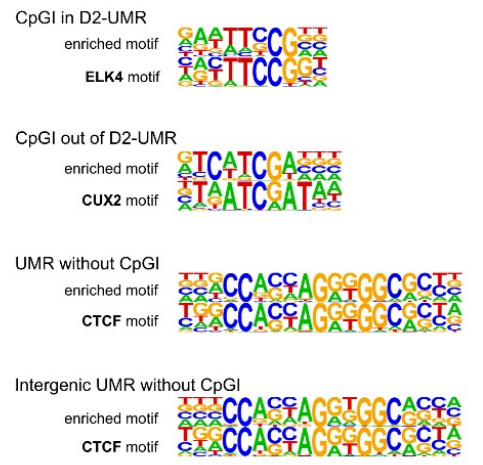

b

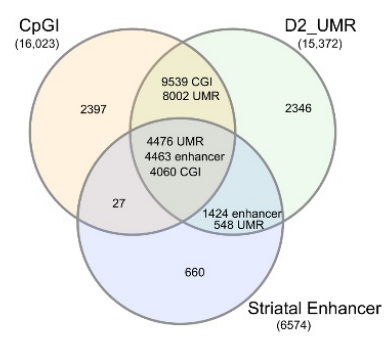

e

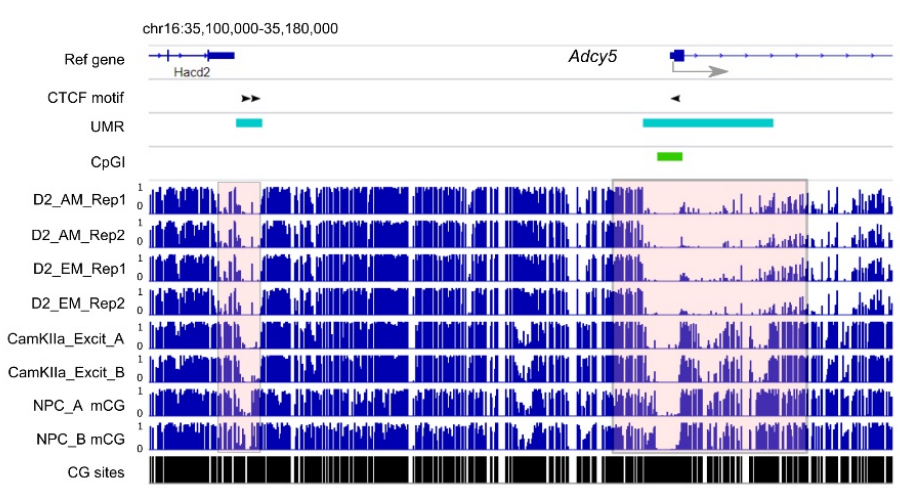

Figure 3. Characterization of NAc D2-MSN UMRs. (a) Genomic feature distribution of NAc D2-MSN UMRs. They are mostly located in TSS-proximal regions, including "Promoter-TSS", "5'-UTR", "First exon", and "First intron". (b) D2-MSN UMRs significantly overlap with CGIs and striatal enhancers. (c) Histone modification enrichments at D2-MSN UMRs. H3K4me1, H3K4me3, H3K27ac, H3K27me3, H3K9me2, H3K36me3 Chromatin IP signals are presented along up- and down-stream $5 \mathrm{~kb}$ regions of UMR sites. RPKM normalization is performed across all histone ChIP-seq data. (d) The top enriched motif sequence and matched transcription factor in each of the four categories of CGI/UMR regions. CGI in D2-UMR: CpG islands located in D2-MSN UMRs; CGI out of D2-UMR: CpG islands located outside of D2-MSN UMRs; UMR without CGI: D2-MSN UMRs that do not have a CpG island inside; intergenic UMR without CGI: intergenic D2-MSN UMRs that do not have a CpG island inside. (e) Adcy5 locus with two neighboring D2-MSN UMRs. The proximal UMR overlaps with a CGI and the distal UMR does not. The two shaded areas highlight regions with cell type-specific differential methylation. D2: D2-MSNs. CamKIIa_Excit: PFC CamKIIa+ excitatory neurons. NPC: neural progenitor cells. AM: AM-seq. EM: EM-seq. CG sites lane shows the CpG frequency. Black arrowhead indicates a CTCF motif in UMR regions.

To gather biological insight of D2-MSN UMRs, we then performed de novo motif analysis at four genomic feature regions: 1. "CGI in UMR" (CpG islands located in D2-MSN UMRs), 2. "CpG out of UMR" (CpG islands located outside of D2-MSN UMRs), 3. "UMR without CGI" (D2-MSN UMRs that do not have a CpG island inside), or 4. "Intergenic UMR without CGI" (intergenic D2-MSN UMRs that do not have a CpG island inside) (Table S5). The enriched motifs in the four categories of regions were matched to dozens of DNA binding proteins (Table S6). For example, the highest ranked motifs for CGIs in UMRs (i.e., low methylation level at these CGIs) belonged to the ELK of the ETS family. In CGIs out of UMR, the top motif is CUX2, indicating accumulation of DNA methylation silencing around those regions in D2-MSNs (Figure 3d). The most significantly enriched motif in UMRs without CGI was matched to CTCF [72], and CTCF motif enrichment was also ranked first in intergenic UMRs without CGI (Figure 3d), which suggests an interplay between DNA methylation and higher order chromosomal organization in D2-MSNs. A representative example is shown near Adcy5 (Figure 3e), a gene in which mutation is associated with various brain disorders [73]. This gene has one upstream distal UMR, which does not overlap with a CGI, and another UMR that runs across the TSS and does overlap with a CGI. Two CTCF binding sites were predicted in the distal UMR, and one such motif 
existed in the proximal UMR. In comparison to published methylome datasets from mouse neural progenitor cells (NPCs) [57] and mouse prefrontal cortex (PFC) CamKIIa+ excitatory neurons [22], we found both UMRs have differential methylation patterns among the three cell types, with robust hypomethylation in D2-MSNs. Therefore, such UMR-specific methylation changes demonstrate methylation dynamics that are specific to D2-MSNs.

Furthermore, we performed pathway analyses of these four categories of UMR related genomic regions in D2-MSNs [74]. We found that the 13,550 genomic regions in the "CGIs within UMR" category covered a broad range of genes and biological pathways (Figure S4b, Table S7), whereas the other three categories were enriched with limited numbers of specific pathways. "CGIs outside UMR" were mainly associated with genes in the "Hippo signaling pathway" and "Signaling pathways regulating pluripotency of stem cells" pathways, which is consistent with the notion that DNA methylation represses pluripotency genes in mature neurons. Genes associated with "UMR without CGI" also had pertinent pathways enriched, such as "oxytocin signaling pathway", "glutamatergic synapse", and "long-term depression". Interestingly, the GO term "alcoholism" was enriched in genes associated with the "CGI-free intergenic UMR" category, including Shc3, Shc4, Araf, Fosb, Hdac11, Adcy5, Creb3l2, Gnai2, Grin2d, and Ppp1r1b. This suggests a regulatory role of intergenic region D2-MSN-specific DNA methylation in alcohol addiction.

\subsection{D2-MSN Specific CpG Differential Methylation Regions (DMRs)}

To further explore D2-MSN regulatory regions beyond UMRs, we performed differential CpG methylation analysis by comparing our data to the methylomes of postnatal day 3-4 mouse NPCs [57], and CamKIIa+ excitatory neurons from PFC of 8-14 weeks old adult male mice [22]. Both datasets were generated using the MethylC-seq protocol [75] with around seven-fold coverage of each strand. Compared to accumbal D2-MSNs, the global CpG methylation level was about $2 \%$ lower in NPCs $(\sim 78.5 \%)$ and slightly higher (less than $1 \%$ ) in excitatory neurons $(81.2 \%$ and $81.4 \%$ for two replicates). Furthermore, we identified 24,284 CpG DMRs between D2-MSN and NPC methylomes, with the majority of them $(21,854)$ being hypomethylated in D2-MSNs (Figure 4a, Table S8), supporting the concept of accumulation of global methylation during cell differentiation with widespread depletion of methylation at regulatory regions $[57,76,77]$. When compared to PFC excitatory neurons, we identified 30,660 CpG DMRs with 10,440 hypomethylatedDMRs and 20,220 hypermethylatedDMRs (Figure 4a, Table S9) in D2-MSNs. Most of these CpG DMRs were located within distal introns and intergenic regions (Figure S5a).

We then performed a K-means clustering analysis to classify all autosomal CpG DMRs into seven clusters (Figure 4a, Table S10). We observed that the four libraries were better clustered together by biological replicates than by methods. This was further confirmed by PCA analysis (Figure S5b). Based on the methylation status in comparison to PFC excitatory neurons and NPCs, the D2-MSN hypomethylation CpG DMRs were classified into four clusters (clusters 1 to 4), while the D2-MSN hypermethylation CpG DMRs were separated into three clusters (clusters 5 to 7) (Figure 4a). CpG DMRs of clusters 1, 2, and 4 represent regions where CpG methylation is significantly depleted in D2-MSNs compared to the other two cell types. DMRs in cluster 3 show reduced methylation levels in both D2-MSNs and PFC excitatory neurons when compared to NPCs. Though fewer in number, the cluster $5 \mathrm{CpG}$ DMRs represent genomic regions that gained CpG methylation in both NAc D2-MSNs and PFC excitatory neurons. DMRs in cluster 6 represent divergent hypermethylation in D2-MSNs and hypomethylation in PFC excitatory neurons stemming from moderate DNA methylation in NPCs. Lastly, cluster 7 shows regions with contrasting hypermethylation in D2-MSNs and hypomethylation in PFC neurons and NPCs (Figure 4a). Using ontology analysis, we found each of the seven DMR clusters was enriched with a defined set of biological process terms (Figure 4b). Generally, genes associated with hypomethylation in NAc D2-MSNs (e.g., clusters 1, 2, 3, and 4) were mostly enriched with various terms related to neuronal functions (Figure 4b, Table S11), such as "cAMP/cGMP catabolic process", "dopamine receptor signaling", "ion transport", "learning", and "behavior". In contrast, 
genes associated with hypermethylated DMRs in both NAc D2-MSNs and PFC excitatory neurons (cluster 5) were enriched with terms related to "maintenance of cell number", "glial cell fate commitment", and "somatic stem cell population maintenance". In addition, genes associated with PFC-specific hypomethylated DMRs (clusters 6, 7) demonstrated enrichments in "long-term synaptic potentiation", "forebrain neuron fate commitment", "limbic system development", and "apoptotic process involved in development". Together, this suggests that D2-MSN-specific DNA methylation changes may play dual roles in both cell fate commitment during development and biological function specification.

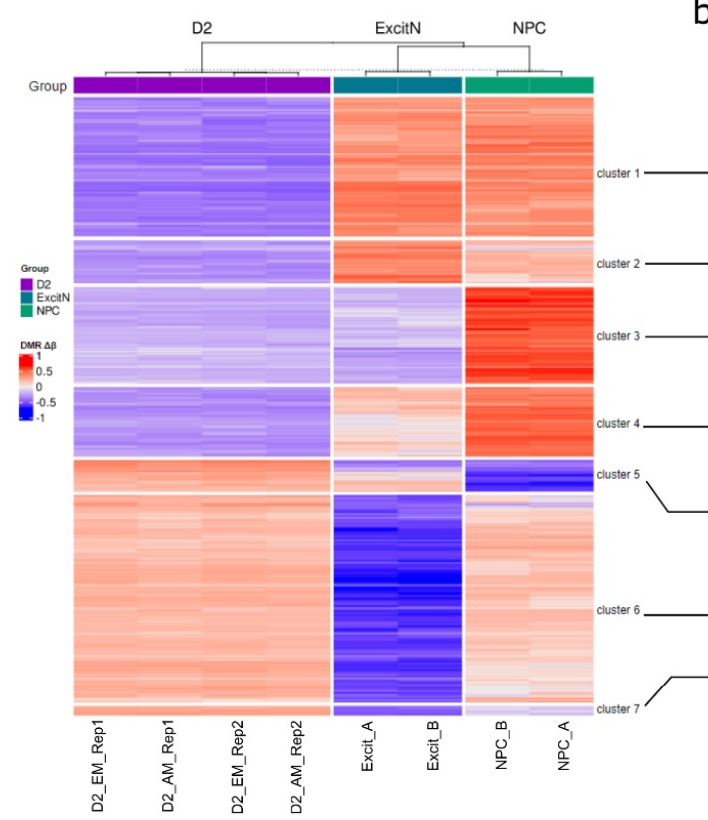

d

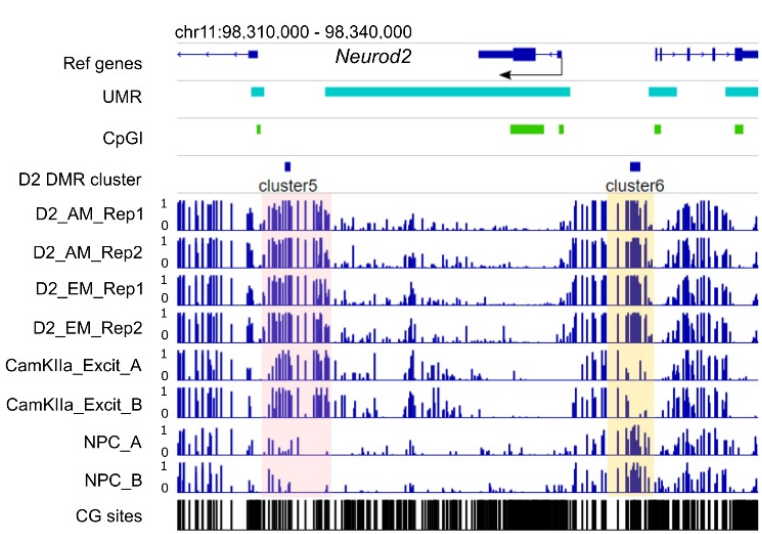

GO: Biological Process

\begin{tabular}{|c|c|c|}
\hline $\begin{array}{l}\text { cAMP/cGMP catabolic process, } \\
\text { striatum development, } \\
\text { visual learning, visual behavior, } \\
\text { regulation of circadian sleep/wake cycle }\end{array}$ & $\begin{array}{l}\text { MEIS1 } \\
\text { ELK4 }\end{array}$ & $\begin{array}{l}\text { EVX2 } \\
\text { EGR2 }\end{array}$ \\
\hline $\begin{array}{l}\text { visual learning, visual behavior, } \\
\text { behavioral response to ethanol, } \\
\text { adenylate cyclase-activating dopamine- } \\
\text { receptor signaling pathway }\end{array}$ & $\begin{array}{l}\text { MEIS1 } \\
\text { SOX4 }\end{array}$ & $\begin{array}{c}\text { NKX4 } \\
\text { FOS::JUNB }\end{array}$ \\
\hline $\begin{array}{l}\text { actin cytoskeleton organization, } \\
\text { calcium ion transpor, } \\
\text { long-term synaptic potentiation }\end{array}$ & $\begin{array}{c}\text { MEF2 } \\
\text { FOS::JUNB }\end{array}$ & $\begin{array}{c}\text { EGR2 } \\
\text { ARNT::H1F }\end{array}$ \\
\hline $\begin{array}{l}\text { actomyosin structure organization, } \\
\text { actin cytoskeleton reorganization, } \\
\text { visual behavior, visual learning }\end{array}$ & $\begin{array}{l}\text { EGR2 } \\
\text { MEIS1 }\end{array}$ & $\begin{array}{c}\text { MEF2 } \\
\text { FOS::JUNB }\end{array}$ \\
\hline $\begin{array}{l}\text { glial cell fate commitment, } \\
\text { maintenance of cell number, } \\
\text { somatic stem cell population maintenance }\end{array}$ & $\begin{array}{l}\text { NF1 } \\
\text { LHX1 }\end{array}$ & $\begin{array}{l}\text { SOX10 } \\
\text { sox8 }\end{array}$ \\
\hline $\begin{array}{l}\text { long-term synaptic potentiation, } \\
\text { corpus callosum development, } \\
\text { forebrain neuron fate commitment }\end{array}$ & $\begin{array}{l}\text { NEUROD2 } \\
\text { NF1 }\end{array}$ & $\begin{array}{c}\text { MEF2 } \\
\text { ARNT::HIF }\end{array}$ \\
\hline $\begin{array}{l}\text { limbic system development, } \\
\text { neural precursor cell proliteration, } \\
\text { apoptotic process involved in develop }\end{array}$ & $\begin{array}{l}\text { NEUROD2 } \\
\text { TBP }\end{array}$ & $\begin{array}{l}\text { NF1 } \\
\text { MAFB }\end{array}$ \\
\hline
\end{tabular}

e

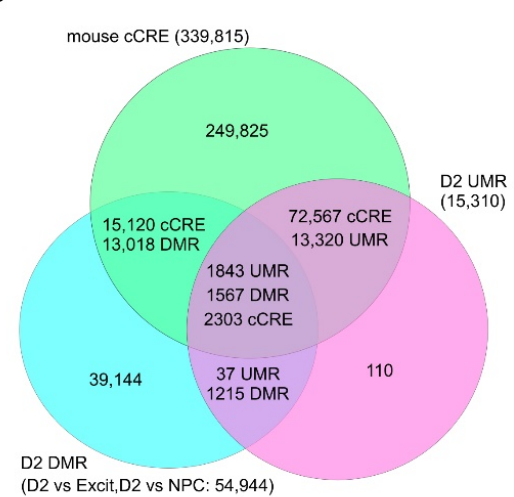

Figure 4. NAc D2-MSN-specific CpG DMRs. (a) K-means clustering of 51,704 NAc D2-MSN-specific autosomal CpG DMRs, in comparison to NPCs and PFC CamKIIa+ excitatory neurons. Two sets of DMRs are combined. For each DMR, the delta $\beta$ values of individual samples (compared to the average methylation level across all samples) are used for clustering. (b) Representative biological process gene ontology (GO) terms enriched with genes associated with each cluster of CpG DMRs in panel a. (c) Transcription factors (TFs) with matched sequences of the top 4 motifs enriched in each of the seven CpG DMR clusters. Identical or similar transcription factors are in the same color, except where black is used for motifs only recognized in a single cluster. (d) The genomic locus of Neurod2 is a representative of transcription factor genes enriched in D2-MSN hyper CpG DMRs with D2-MSN-specific hypermethylation. The shaded regions indicate notable cell type-specific differential methylation when compared to NPCs or PFC excitatory neurons. (e) UMRs and cell type-specific DMRs are largely overlapped with mouse cCREs. D2: D2-MSNs. CamKIIa_Excit: PFC CamKIIa+ excitatory neurons. NPC: neural progenitor cells. AM: AM-seq. EM: EM-seq. 
Next, we carried out a motif analysis to identify the transcription factors that may be associated with methylome remodeling (Figure 4c, Table S12). We found that each of the seven clusters was enriched with a unique set of transcription factor binding motifs. Among them, AP-1 transcription complex (FOSB::JUNB) motifs were one of the top hits in clusters 2, 3, and 4. Motifs of EGR2, MEF2, MEIS1, and NF1 were also enriched in three clusters. Notably, AP-1 is a heterodimer of the FOS family and JUN family and has been recognized as a key transcription factor in addiction and stress response [78-80]. In particular, FOS family genes are transiently induced in NAc by acute drug exposure, with a truncated form of FOSB $(\triangle \mathrm{FOSB})$ demonstrating a lasting accumulation [32,81]. The immediate early genes EGR2 and EGR1 have also been implicated in drug response and may be subjected to drug-induced DNA methylation changes as well [82-84]. Similarly, MEF2 in NAc has also been reported to regulate synapse plasticity and sensitized responses to cocaine [85]. The enrichment of these motifs in D2-MSN CpG DMRs not only supports the functional roles of the relevant transcription factors in drug addiction but also implies a D2-MSN-specific function that is DNA methylation dependent.

In addition, we recognized that some motif enriched transcription factors themselves were subjected to DNA methylation changes. For example, the NEUROD2 motif was highly enriched in clusters 6 and 7 of D2-MSN DMRs (Figure 4c), which was accompanied by two hypermethylated DMRs near the Neurod2 gene (Figure 4d); the upstream DMR was heavily methylated in NAc D2-MSNs but had moderate methylation in NPCs and low methylation in PFC excitatory neurons, while the downstream DMR showed hypermethylation in both neuronal cell types.

By comparing the methylation-related regulatory regions that we identified as UMRs and CpG DMRs with the curated set of mouse candidate cis-regulatory elements (cCREs) from the ENCODE project [86], we found that almost all UMRs overlapped with one or more cCRE. Out of the 15,310 UMRs, 15,163 overlapped with 74,870 cCREs, and 14,585 D2-MSN CpG DMRs overlapped with 17,423 cCREs (Figure 4e). Furthermore, a total of 1567 D2 CpG DMRs were located in 1843 UMR regions covering 2303 cCREs. This further supports the regulatory role of DNA methylation in cell identity and function in NAc D2-MSNs.

\subsection{D2-MSN non-CpG DMRs}

We then analyzed non-CpG methylation in NAc D2-MSNs by comparing them to NPC and PFC excitatory neurons, respectively. Mammalian non-CpG methylation accumulates during development, remains prevalent in neurons, and is inversely correlated with gene transcription $[23,87,88]$. Given that the methylomes of NPCs and excitatory neurons were produced by a different protocol (MethylC-seq), we only considered $\mathrm{CpH}$ sites that passed the binomial test in order to mitigate any potential bias that may be derived from methylation profiling methodologies (Figure 2b). We thus confirmed the non-CpG methylation differences among cell types. The NPC methylome had a significantly lower level of global $\mathrm{mCpH}$ (less than $0.001 \%$ ) compared to NAc D2-MSNs and the PFC excitatory neurons, which were both $\sim 1 \%$. As mCpA accounts for the majority of non-CpG methylation, which also highly correlates with total $\mathrm{mCpH}$ methylation, we analyzed $\mathrm{CpA}$ methylation as a representative of non-CpG methylation. We first calculated the gene body CpA methylation levels of all genes. By overlapping the top 1000 ( $5 \%$ of all genes) highly methylated genes in D2-MSNs and PFC excitatory neurons, we found that 349 genes obtained high levels of non-CpG methylation in both cell types. Among them, genes encoding microRNA, transcription factors, and peptide ligands were over-represented (Table S13).

Next, we performed differential analysis with binned CpA methylation windows to identify non-CpG DMRs (996 hypomethylated DMRs, and 5911 hypermethylated DMRs in comparison to PFC CamKIIa+ neurons) (Table S14). We found that the genes associated with hypomethylated non-CpG DMRs were specifically clustered in the ontology categories related to D2-MSN functions, such as "gamma-aminobutyric acid (GABA) biosynthetic process", "gamma-aminobutyric acid (GABA) metabolic process", "learning or memory", and "dopamine receptor signaling pathway" (Figure S6a, Table S15). In contrast, genes 
associated with hyper non-CpG DMRs were enriched in GO terms mostly related to development or differentiation (Table S15). Given the repressive role of non-CpG methylation on transcription, this suggests these genes were silenced during D2-MSN maturation. For example, dopamine receptor Drd1 and transcription factor Neurod6, which are not expressed in mature D2-MSNs, were found to have hyper non-CpG DMRs (Figure 5a). To further support the functional role of CpA methylation in D2-MSNs, we found non-CpG hypo DMRs in the gene body of two D2-MSN marker genes: Drd2 and Penk. These non-CpG DMRs also appeared to overlap with CpG DMR in the same trend (Figure 5a). Further analysis of all CpG DMRs with non-CpG DMRs demonstrated substantial overlaps between CpG hyper-DMRs ( 9.8\% overlaps) with $\mathrm{mCpA}$ hyper-DMRs ( 27.0\% overlaps), and $\mathrm{mCpG}$ hypo-DMRs ( 2.8\% overlaps) with mCpA hypo-DMRs ( $23.7 \%$ overlaps) (Figure $5 \mathrm{~b})$. By analyzing the $\mathrm{mCpA}$ levels at all $\mathrm{CpG}$ DMR regions, we found that PFC excitatory neurons had significantly decreased CpA methylation at CpG DMRs that were hypermethylated in D2-MSNs, and D2-MSNs hypomethylated DMRs also had significant CpA hypomethylation (Figure $5 c$ ). In light of the observed synergy, we performed a regression analysis between $\mathrm{CpG}$ methylation and non-CpG methylation levels at CpG DMRs. The results presented a moderate correlation (0.475-0.645) between the two modalities in CpG DMRs. The CpG methylation can explain $\sim 42 \%$ variance of $\mathrm{CpA}$ methylation in excitatory neurons, and $22-25 \%$ variance in D2-MSNs (Figure S6b).
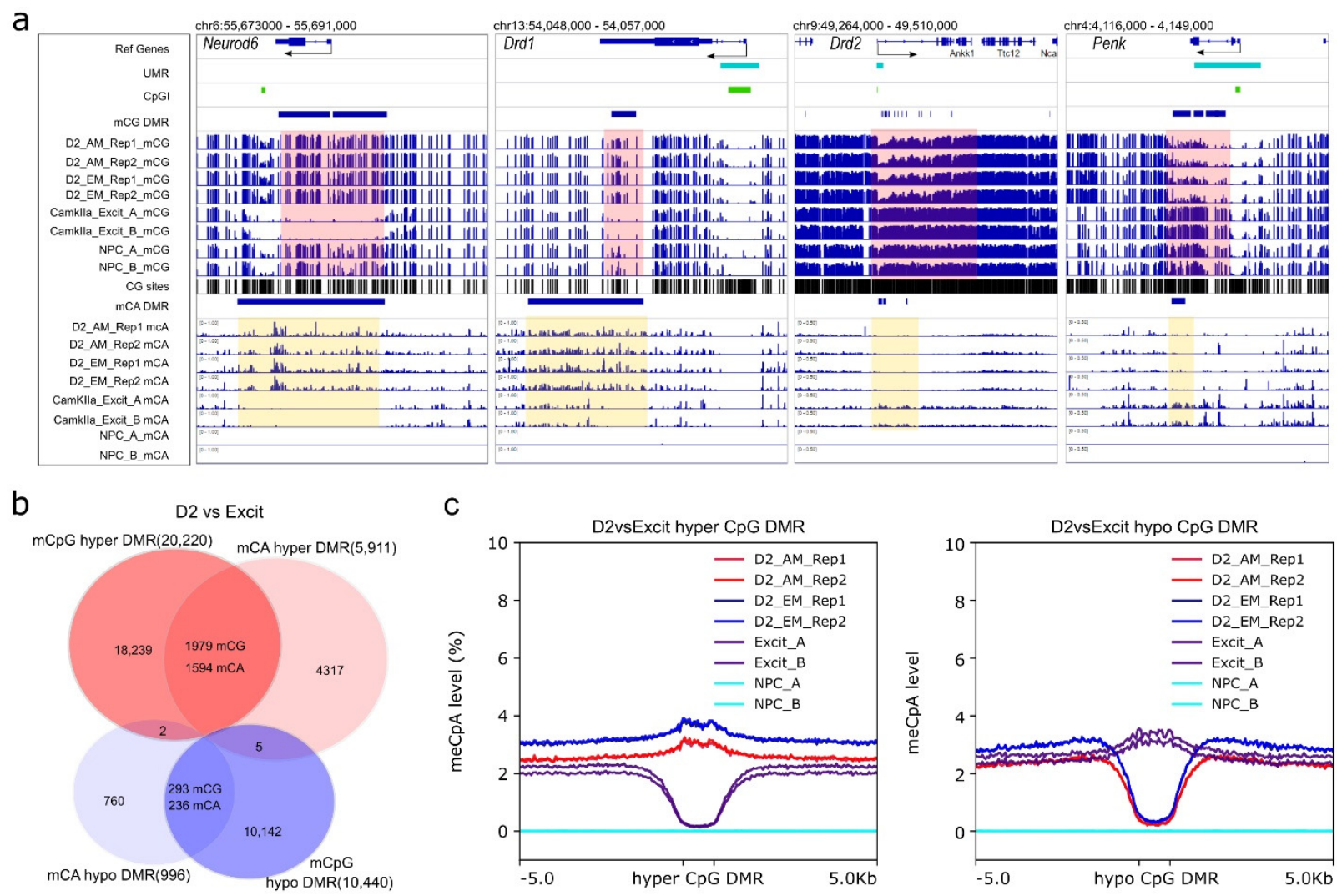

Figure 5. NAc D2-MSN-specific non-CpG DMRs. All non-CpG DMRs are identified by comparing NAc D2-MSNs to PFC CamKIIa+ excitatory neurons (D2 vs. Excit). (a) Representative view of Drd1 and Neurod6 loci with CpG and CpA hypermethylation in D2-MSNs. In contrast, D2-MSN marker genes Drd2 and Penk have CpG and CpA hypomethylation along their genomic loci when compared to PFC CamKIIa+ excitatory neurons. Pink-shaded regions highlight CpG DMR regions, yellow-shaded regions highlight $\mathrm{CpA} D \mathrm{DMR}$ regions. $\beta$ value range of all $\mathrm{CpG}$ lanes is $0-1$. $\beta$ value range of CpA for Neurod6 and Drd1 is $0-1$. $\beta$ value range of CpA for Drd2 and Penk is $0-0.5$. NPC has virtually no CpA methylation. (b) CpG DMRs and CpA DMRs are significantly overlapped. (c) CpA 
methylation levels at CpG DMRs. Left: CpA methylation levels of D2 hyper-methylated CpG DMRs (blue and red) are noticeably higher than surrounding regions in D2-MSNs and much lower in PFC excitatory neurons (purple). Right: The CpA methylation levels of D2 hypo-methylated CpG DMRs are much lower in D2-MSNs (blue and red) and are discernibly higher in PFC excitatory neurons(purple) compared to the adjacent regions. The NPC methylome is devoid of non-CpG methylation (cyan).

\section{Discussion}

In this study, we characterized the mouse NAc D2-MSN methylomes using two different methods, namely AM-seq and EM-seq, using the Swift Accel-NGS Methyl-Seq DNA Library Kit and the NEB Enzymatic Methyl-seq Kit, respectively. Our side-byside comparison demonstrates good consistency and reproducibility between the two methods. We found the library quality and yields, global methylation and loci specific methylation, and potential biases were all highly comparable between the two methods. AM-seq or EM-seq was compared to other methods, such as MethyC-seq [89], QIAseq [63], and PBAT [90], with better performance. However, as both methods were suitable to handle lower amounts of DNA (ng scale), a direct comparison between the two will be helpful when deciding on a method for whole-genome methylome profiling with low cell numbers, such as neuronal subtypes from discrete brain regions. In studies with brain tissue, methylation landscapes of different neural cell types are usually superimposed, which inevitably obscures epigenetic changes that are often cell type-specific, given the remarkable neuronal heterogeneity in the brain. Therefore, brain cell type-specific methylation profiling is necessary to aid our understanding of the functional role of DNA methylation in the brain. Using D2-MSNs from mouse nucleus accumbens as an example, our study shows that these two methods are comparable and suitable for methylome profiling of low-input DNA samples (i.e., $40 \mathrm{ng}$ DNA extracted from D2-MSNs isolated from NAc of a single mouse). We found the CPG methylation levels to be closely correlated not only between biological replicates, but also between the two methods. A similar correlation also holds for non-CpG methylation. Notably, both AM-seq and EM-seq detected the subtle difference in global CpG methylation levels between Rep 1 and Rep 2. Moreover, D2-MSN CpG DMRs were slightly more separated according to biological replicates than methods in the first principal component of PCA analysis, indicating that methylation variations between individual mice were similarly detected by both methods. However, it should be noted that the methylomes generated from the two methods were not identical. For example, the library yield of EM-seq was substantially higher than AM-seq, considering EM-seq took two fewer PCR amplification cycles to generate similar amounts of libraries from AM-seq. The library yield with less amplification cycles is beneficial for library complexity, which is also supported by our analysis. In addition, we found that EM-seq libraries had a larger insert size, which should contribute to better data yield and mapping ratio, and generated more valid reads under the same expense. While optimization is possible for both methods, we have followed the default library preparation protocols and sonicated the gDNA into the recommended fragmentation sizes (350 bp for AM-seq, $270 \mathrm{bp}$ for EM-seq). The eventual shorter library inserts in AM-seq could be attributed to the DNA destruction under sodium bisulfite treatment. Moreover, AM-seq had a slightly higher unique mapping ratio and over-conversion rate of $\mathrm{mCpG}$, while the two protocols exhibited different dinucleotide preferences of non-conversion and coverage bias per GC content. Despite the subtle individual differences between the two biological replicates, we have observed good consistency among our methylome datasets. A recent study reported the single-cell methylome profiling of the mouse cortex, which identified 161 cell clusters including D1-MSNs and D2-MSNs based upon the methylation status of marker genes [91]. Our datasets provide a valuable reference with a different cell isolation strategy and high genomic coverage. In addition, we need to point out that neither of the two methods we applied in this study can distinguish methylated cytosine from its oxidative derivatives. As sodium bisulfite does not convert 5-hydroxymethylcytosine (5hmC), $5 \mathrm{hmC}$ cannot be 
separated from 5-methylcytosine ( $5 \mathrm{mC})$ in AM-seq. Furthermore, the methylated cytosine callings in EM-seq may not be distinguished from $5 \mathrm{hmC}$, 5 -formylcytosine $(5 \mathrm{fC})$, nor 5 -carboxylcytosine (5caC) [40]. Since $5 \mathrm{hmC}$ is most abundant in the brain [23,92-94], it would be beneficial to chart $5 \mathrm{hmC}$ at base-resolution in MSNs in the future. Though $5 \mathrm{fC}$ and $5 \mathrm{caC}$ are only present at extremely low levels [95], whether they contributed to the methylation differences between AM-seq and EM-seq deserves further investigation.

The gain of non-CpG methylation in neuronal cells is known to have a repressive effect on gene expression, possibly through MECP2 [23,88,96-100]. Notably, we found that the hyper- and hypo- non-CpG methylation regions in D2-MSNs appear to be enriched with contrasting functionally distinct gene categories. Additionally, the selective deposition and depletion of non-CpG methylation are in accordance with the notion that non-CpG methylation may serve as a fine-tuning mechanism in brain function. We found a significant overlap between D2-MSN CpG DMRs and non-CpG DMRs, with a moderate correlation between $\mathrm{CpG}$ and non-CpG methylation levels in those $\mathrm{CpG}$ DMR regions. This noticeable synergy might result from shared gene transcriptional activity or other local epigenetic modalities.

In NAc, the two types of principal neurons, D1-MSNs and D2-MSNs, belong to distinct neural circuits $[35,101,102]$. It has long been recognized that D1- and D2-MSNs not only have unique molecular signatures that mediate their respective functions [103,104], but also play contrasting roles in behaviors. For example, activation of D2-MSNs inhibits reward and motivational behaviors [105-107], whereas activation of D1-MSNs promotes the responses. Notably, the NAc neuronal methylome was recently reported to be more distinct compared to the ones from other brain regions, with the differential methylation regions being highly enriched for heritability of addictive behaviors $[60,108]$. The DNA modification enzymes were also subjected to expression changes in NAc after cocaine exposure, which may alter neural plasticity and genome-wide DNA modification landscapes $[109,110]$. With such accumulating evidence, to study neuron subtype-specific roles of DNA epigenetics in NAc medium spiny neurons becomes necessary. Through the characterization of NAc D2-MSN methylome, and its comparison to NPCs and PFC excitatory neurons, we identified numerous regulatory regions that include 15,310 UMRs and 54,944 D2-MSN-specific CPG DMRs. Almost all UMRs and about one-fourth of D2-MSN CpG DMRs overlapped with at least one CCRE curated by the ENCODE project, which indicates the important role of DNA methylation in D2-MSN functions. For example, the motif analysis of UMRs lacking a CGI has shown an enrichment of CTCF binding. CTCF plays pivotal roles in higher-order genome architecture $[72,111]$ that may mediate a broad range of cellular functions $[112,113]$. The DNA binding affinity of CTCF was found to be negatively affected by DNA methylation [114-116]. Crystal structure analysis [117] and direct binding assays $[118,119]$ further supported that CpG methylation inhibits the DNA binding affinity of CTCF. Recently, growing evidence indicates the role of chromatin architecture in brain disorders, such as addiction [120-123]. For example, cocaine exposure was found to increase DNA methylation, decrease CTCF binding, and inhibit the threedimensional looping interaction between the Auts2 and Caln 1 genes in mouse nucleus accumbens, which was associated with D2-MSN-specific upregulation of Auts2 [124]. In addition, a smoking-related DNA methylation change was found near the CTCF locus in postmortem NAc tissue [125]. Our identification of CTCF motif enrichment in NAc D2-MSN-specific UMRs and the recognition of an "alcoholism" pathway within the same UMR category suggests D2-MSN-specific interplay between DNA methylation and higher order chromatin architecture in addiction [122].

\section{Conclusions}

Taken together, we performed a comparison of two methylome profiling methods using 40 ng DNA from mouse NAc D2-MSNs. Though the two methods are based upon distinct chemistries, the methylome data generated from them were highly comparable. 
We therefore provided a valuable resource of the neuron subtype-specific methylome of mouse nucleus accumbens D2-MSNs.

Supplementary Materials: The following supporting information can be downloaded at: https: / / www.mdpi.com/article/10.3390/genes13020306/s1. Figure S1: D2-MSN FACS plots and qPCR validation, Figure S2: D2-MSN AM-seq and EM-seq quality analysis, Figure S3: NAc D2-MSN methylome characterization, Figure S4: D2-MSN UMR analysis, Figure S5: NAc D2-MSN-specific CpG DMRs, Figure S6: NAc D2-MSN non-CpG methylation, Table S1: DNA input and yield of D2-MSN methylomes, Table S2: Sequencing reads processing, Table S3: Statistics of the four D2-MSN methylomes, Table S4: D2-MSN unmethylated regions (UMRs), Table S5: Four categories of CGI/UMR related genomic regions, Table S6: Transcription factor motifs enriched in CGI/UMR regions, Table S7: List of KEGG pathways enriched in genes associated with four categories of CGI/UMR regions, Table S8: CpG DMRs of D2-MSNs vs. NPCs, Table S9: CpG DMRs of D2-MSNs vs. PFC CamKIIa+ neurons. Table S10: D2-MSN autosomal CpG DMRs used for K-means clustering analysis, Table S11: List of enriched GO terms for seven clusters of D2-MSN CpG DMRs, Table S12: Transcription factors matched by D2-MSN CpG DMR motif analysis, Table S13. Genes with high non-CpG methylation in both D2-MSNs and PFC excitatory neurons, Table S14: Non-CpG methylation DMRs comparing D2-MSNs to PFC CamKIIa+ neurons, Table S15: List of enriched GO terms for D2-MSN non-CpG DMRs.

Author Contributions: J.F. and Y.L. conceived the work. J.F. supervised the project. H.X. prepared the animal and collected animal tissue samples. J.M.C. and Y.L. developed the FACS dissociation protocol and collected cell samples. Y.L. isolated DNA, performed AM-seq and EM-seq, and generated the D2-MSN methylome dataset. Y.L. performed the bioinformatics analyses. J.M.C. performed the qPCR validation. J.F. and Y.L. interpreted the results. Y.L. designed the figures, prepared data visualization, and drafted the manuscript. J.F. and Y.L. wrote the manuscript with contributions from H.X. and J.M.C. All authors have read and agreed to the published version of the manuscript.

Funding: This work was supported by the National Institutes of Health (Grant Nos. DP1 DA046587 and R01 DA046720 [to J.F.]). J.M.C. is a recipient of an FSU Legacy Fellowship.

Institutional Review Board Statement: Not applicable.

Informed Consent Statement: Not applicable.

Data Availability Statement: The raw reads files and processed data were deposited to the NCBI Gene Expression Omnibus with accession number GSE195752.

Acknowledgments: We thank all members of the Feng Lab for supports of this study.

Conflicts of Interest: The authors declare no conflict of interest.

\section{References}

1. Goll, M.G.; Bestor, T.H. Eukaryotic Cytosine Methyltransferases. Annu. Rev. Biochem. 2005, 74, 481-514. [CrossRef] [PubMed]

2. Bird, A. DNA Methylation Patterns and Epigenetic Memory. Genes Dev. 2002, 16, 6-21. [CrossRef] [PubMed]

3. Li, E.; Beard, C.; Jaenisch, R. Role for DNA Methylation in Genomic Imprinting. Nature 1993, 366, 362-365. [CrossRef] [PubMed]

4. Zhang, Y.; Xiang, Y.; Yin, Q.; Du, Z.; Peng, X.; Wang, Q.; Fidalgo, M.; Xia, W.; Li, Y.; Zhao, Z.; et al. Dynamic Epigenomic Landscapes during Early Lineage Specification in Mouse Embryos. Nat. Genet. 2017, 50, 96-105. [CrossRef]

5. Lunyak, V.V.; Rosenfeld, M.G. Epigenetic Regulation of Stem Cell Fate. Hum. Mol. Genet. 2008, 17, R28-R36. [CrossRef]

6. Kohli, R.M.; Zhang, Y. TET Enzymes, TDG and the Dynamics of DNA Demethylation. Nature 2013, 502, 472-479. [CrossRef]

7. Smith, Z.D.; Meissner, A. DNA Methylation: Roles in Mammalian Development. Nat. Rev. Genet. 2013, 14, 204-220. [CrossRef]

8. Santos, F.; Hendrich, B.; Reik, W.; Dean, W. Dynamic Reprogramming of DNA Methylation in the Early Mouse Embryo. Dev. Biol. 2002, 241, 172-182. [CrossRef]

9. Monk, M.; Boubelik, M.; Lehnert, S. Temporal and Regional Changes in DNA Methylation in the Embryonic, Extraembryonic and Germ Cell Lineages during Mouse Embryo Development. Development 1987, 99, 371-382. [CrossRef]

10. Lyko, F. The DNA Methyltransferase Family: A Versatile Toolkit for Epigenetic Regulation. Nat. Rev. Genet. 2017, 19, 81-92. [CrossRef]

11. Xu, G.L.; Bochtler, M. Reversal of Nucleobase Methylation by Dioxygenases. Nat. Chem. Biol. 2020, 16, 1160-1169. [CrossRef] [PubMed]

12. Lindsay, S.; Bird, A.P. Use of Restriction Enzymes to Detect Potential Gene Sequences in Mammalian DNA. Nature 1987, 327, 336-338. [CrossRef] [PubMed] 
13. Keshet, I.; Schlesinger, Y.; Farkash, S.; Rand, E.; Hecht, M.; Segal, E.; Pikarski, E.; Young, R.A.; Niveleau, A.; Cedar, H.; et al. Evidence for an Instructive Mechanism of de Novo Methylation in Cancer Cells. Nat. Genet. 2006, 38, 149-153. [CrossRef] [PubMed]

14. Zhang, X.; Yazaki, J.; Sundaresan, A.; Cokus, S.; Chan, S.W.L.; Chen, H.; Henderson, I.R.; Shinn, P.; Pellegrini, M.; Jacobsen, S.E.; et al. Genome-Wide High-Resolution Mapping and Functional Analysis of DNA Methylation in Arabidopsis. Cell 2006, 126, 1189-1201. [CrossRef]

15. Frommer, M.; McDonald, L.E.; Millar, D.S.; Collis, C.M.; Watt, F.; Grigg, G.W.; Molloy, P.L.; Paul, C.L. A Genomic Sequencing Protocol That Yields a Positive Display of 5-Methylcytosine Residues in Individual DNA Strands. Proc. Natl. Acad. Sci. USA 1992, 89, 1827-1831. [CrossRef]

16. Susan, J.; Harrison, J.; Paul, C.L.; Frommer, M. High Sensitivity Mapping of Methylated Cytosines. Nucleic Acids Res. 1994, 22, 2990-2997. [CrossRef]

17. Lister, R.; O’Malley, R.C.; Tonti-Filippini, J.; Gregory, B.D.; Berry, C.C.; Millar, A.H.; Ecker, J.R. Highly Integrated Single-Base Resolution Maps of the Epigenome in Arabidopsis. Cell 2008, 133, 523-536. [CrossRef]

18. Cokus, S.J.; Feng, S.; Zhang, X.; Chen, Z.; Merriman, B.; Haudenschild, C.D.; Pradhan, S.; Nelson, S.F.; Pellegrini, M.; Jacobsen, S.E. Shotgun Bisulphite Sequencing of the Arabidopsis Genome Reveals DNA Methylation Patterning. Nature 2008, 452, 215-219. [CrossRef]

19. Harris, R.A.; Wang, T.; Coarfa, C.; Nagarajan, R.P.; Hong, C.; Downey, S.L.; Johnson, B.E.; Fouse, S.D.; Delaney, A.; Zhao, Y.; et al. Comparison of Sequencing-Based Methods to Profile DNA Methylation and Identification of Monoallelic Epigenetic Modifications. Nature Biotechnology 2010, 28, 1097-1105. [CrossRef]

20. Bock, C.; Tomazou, E.M.; Brinkman, A.B.; Müller, F.; Simmer, F.; Gu, H.; Jäger, N.; Gnirke, A.; Stunnenberg, H.G.; Meissner, A Quantitative Comparison of Genome-Wide DNA Methylation Mapping Technologies. Nature Biotechnology 2010, 28, 1106-1114. [CrossRef]

21. Olova, N.; Krueger, F.; Andrews, S.; Oxley, D.; Berrens, R.V.; Branco, M.R.; Reik, W. Comparison of Whole-Genome Bisulfite Sequencing Library Preparation Strategies Identifies Sources of Biases Affecting DNA Methylation Data. Genome Biology 2018, 19, 33. [CrossRef] [PubMed]

22. Mo, A.; Mukamel, E.A.; Davis, F.P.; Luo, C.; Henry, G.L.; Picard, S.; Urich, M.A.; Nery, J.R.; Sejnowski, T.J.; Lister, R.; et al. Epigenomic Signatures of Neuronal Diversity in the Mammalian Brain. Neuron 2015, 86, 1369-1384. [CrossRef] [PubMed]

23. Lister, R.; Mukamel, E.A.; Nery, J.R.; Urich, M.; Puddifoot, C.A.; Johnson, N.D.; Lucero, J.; Huang, Y.; Dwork, A.J.; Schultz, M.D.; et al. Global Epigenomic Reconfiguration during Mammalian Brain Development. Science 2013, 341, 1237905. [CrossRef] [PubMed]

24. Xie, W.; Barr, C.L.; Kim, A.; Yue, F.; Lee, A.Y.; Eubanks, J.; Dempster, E.L.; Ren, B. Base-Resolution Analyses of Sequence and Parent-of-Origin Dependent DNA Methylation in the Mouse Genome. Cell 2012, 148, 816-831. [CrossRef]

25. Luo, C.; Keown, C.L.; Kurihara, L.; Zhou, J.; He, Y.; Li, J.; Castanon, R.; Lucero, J.; Nery, J.R.; Sandoval, J.P.; et al. Single-Cell Methylomes Identify Neuronal Subtypes and Regulatory Elements in Mammalian Cortex. Science 2017, 357, 600-604. [CrossRef]

26. He, Y.; Hariharan, M.; Gorkin, D.U.; Dickel, D.E.; Luo, C.; Castanon, R.G.; Nery, J.R.; Lee, A.Y.; Zhao, Y.; Huang, H.; et al Spatiotemporal DNA Methylome Dynamics of the Developing Mouse Fetus. Nature 2020, 583, 752-759. [CrossRef]

27. Brown, A.N.; Feng, J. Drug Addiction and DNA Modifications. Adv. Exp. Med. Biol. 2017, 978, 105-125. [CrossRef]

28. Cadet, J.L.; Brannock, C.; Krasnova, I.N.; Jayanthi, S.; Ladenheim, B.; McCoy, M.T.; Walther, D.; Godino, A.; Pirooznia, M.; Lee, R.S. Genome-Wide DNA Hydroxymethylation Identifies Potassium Channels in the Nucleus Accumbens as Discriminators of Methamphetamine Addiction and Abstinence. Mol. Psychiatry 2016, 22, 1196-1204. [CrossRef]

29. Starkman, B.G.; Sakharkar, A.J.; Pandey, S.C. Epigenetics-Beyond the Genome in Alcoholism. Alcohol Res. Curr. Rev. $2012,34,293$.

30. Tulisiak, C.T.; Harris, R.A.; Ponomarev, I. DNA Modifications in Models of Alcohol Use Disorders. Alcohol 2017, 60, 19-30. [CrossRef]

31. Kaplan, G.; Xu, H.; Abreu, K.; Feng, J. DNA Epigenetics in Addiction Susceptibility. Frontiers in Genetics 2022, 13, 806685 [CrossRef]

32. Robison, A.J.; Nestler, E.J. Transcriptional and Epigenetic Mechanisms of Addiction. Nat. Rev. Neurosci. 2011, 12, 623-637. [CrossRef] [PubMed]

33. Koob, G.F.; Volkow, N.D. Neurocircuitry of Addiction. Neuropsychopharmacology 2009, 35, 217-238. [CrossRef] [PubMed]

34. Gerfen, C.R.; Engber, T.M.; Mahan, L.C.; Susel, Z.; Chase, T.N.; Monsma, F.J.; Sibley, D.R. D1 and D2 Dopamine Receptor-Regulated Gene Expression of Striatonigral and Striatopallidal Neurons. Science 1990, 250, 1429-1432. [CrossRef]

35. Gerfen, C.R.; Surmeier, D.J. Modulation of Striatal Projection Systems by Dopamine. Annu. Rev. Neurosci. 2011, 34, 441-466. [CrossRef]

36. Adey, A.; Shendure, J. Ultra-Low-Input, Tagmentation-Based Whole-Genome Bisulfite Sequencing. Genome Res. 2012, 22, 1139-1143. [CrossRef]

37. Miura, F.; Enomoto, Y.; Dairiki, R.; Ito, T. Amplification-Free Whole-Genome Bisulfite Sequencing by Post-Bisulfite Adaptor Tagging. Nucleic Acids Res. 2012, 40, e136. [CrossRef]

38. Smallwood, S.A.; Lee, H.J.; Angermueller, C.; Krueger, F.; Saadeh, H.; Peat, J.; Andrews, S.R.; Stegle, O.; Reik, W.; Kelsey, G. Single-Cell Genome-Wide Bisulfite Sequencing for Assessing Epigenetic Heterogeneity. Nat. Methods 2014, 11, 817-820. [CrossRef] 
39. Miura, F.; Shibata, Y.; Miura, M.; Sangatsuda, Y.; Hisano, O.; Araki, H.; Ito, T. Highly Efficient Single-Stranded DNA Ligation Technique Improves Low-Input Whole-Genome Bisulfite Sequencing by Post-Bisulfite Adaptor Tagging. Nucleic Acids Res. 2019, 47, 85. [CrossRef]

40. Zhao, L.Y.; Song, J.; Liu, Y.; Song, C.X.; Yi, C. Mapping the Epigenetic Modifications of DNA and RNA. Protein Cell 2020, 11, 792-808. [CrossRef]

41. Liu, Y.; Siejka-Zielińska, P.; Velikova, G.; Bi, Y.; Yuan, F.; Tomkova, M.; Bai, C.; Chen, L.; Schuster-Böckler, B.; Song, C.X. BisulfiteFree Direct Detection of 5-Methylcytosine and 5-Hydroxymethylcytosine at Base Resolution. Nat. Biotechnol. 2019, 37, 424-429. [CrossRef] [PubMed]

42. Vaisvila, R.; Ponnaluri, V.K.C.; Sun, Z.; Langhorst, B.W.; Saleh, L.; Guan, S.; Dai, N.; Campbell, M.A.; Sexton, B.S.; Marks, K.; et al. Enzymatic Methyl Sequencing Detects DNA Methylation at Single-Base Resolution from Picograms of DNA. Genome Res. 2021, 31, 1280-1289. [CrossRef] [PubMed]

43. Gong, S.; Zheng, C.; Doughty, M.L.; Losos, K.; Didkovsky, N.; Schambra, U.B.; Nowak, N.J.; Joyner, A.; Leblanc, G.; Hatten, M.E.; et al. A Gene Expression Atlas of the Central Nervous System Based on Bacterial Artificial Chromosomes. Nature 2003, 425, 917-925. [CrossRef] [PubMed]

44. Krueger, F.; Andrews, S.R. Bismark: A Flexible Aligner and Methylation Caller for Bisulfite-Seq Applications. Bioinformatics 2011, 27, 1571-1572. [CrossRef] [PubMed]

45. Okonechnikov, K.; Conesa, A.; García-Alcalde, F. Qualimap 2: Advanced Multi-Sample Quality Control for High-Throughput Sequencing Data. Bioinformatics 2016, 32, 292-294. [CrossRef] [PubMed]

46. Karolchik, D.; Hinrichs, A.S.; Furey, T.S.; Roskin, K.M.; Sugnet, C.W.; Haussler, D.; Kent, W.J. The UCSC Table Browser Data Retrieval Tool. Nucleic Acids Res. 2004, 32, D493-D496. [CrossRef]

47. Gao, T.; Qian, J. EnhancerAtlas 2.0: An Updated Resource with Enhancer Annotation in 586 Tissue/Cell Types across Nine Species. Nucleic Acids Res. 2020, 48, D58-D64. [CrossRef]

48. Aken, B.L.; Ayling, S.; Barrell, D.; Clarke, L.; Curwen, V.; Fairley, S.; Fernandez Banet, J.; Billis, K.; García Girón, C.; Hourlier, T.; et al. The Ensembl Gene Annotation System. Database 2016, 2016, baw093. [CrossRef]

49. Quinlan, A.R.; Hall, I.M. BEDTools: A Flexible Suite of Utilities for Comparing Genomic Features. Bioinformatics 2010, 26, 841-842. [CrossRef]

50. Ramírez, F.; Dündar, F.; Diehl, S.; Grüning, B.A.; Manke, T. DeepTools: A Flexible Platform for Exploring Deep-Sequencing Data. Nucleic Acids Res. 2014, 42, W187-W191. [CrossRef]

51. Lister, R.; Pelizzola, M.; Dowen, R.H.; Hawkins, R.D.; Hon, G.; Tonti-Filippini, J.; Nery, J.R.; Lee, L.; Ye, Z.; Ngo, Q.-M.; et al. Human DNA Methylomes at Base Resolution Show Widespread Epigenomic Differences. Nature 2009, 462, 315-322. [CrossRef] [PubMed]

52. Burger, L.; Gaidatzis, D.; Schübeler, D.; Stadler, M.B. Identification of Active Regulatory Regions from DNA Methylation Data Nucleic Acids Res. 2013, 41, e155. [CrossRef] [PubMed]

53. Lutz, P.E.; Chay, M.A.; Pacis, A.; Chen, G.G.; Aouabed, Z.; Maffioletti, E.; Théroux, J.F.; Grenier, J.C.; Yang, J.; Aguirre, M.; et al. Non-CG Methylation and Multiple Histone Profiles Associate Child Abuse with Immune and Small GTPase Dysregulation. Nat. Commun. 2021, 12, 1132. [CrossRef] [PubMed]

54. Heinz, S.; Benner, C.; Spann, N.; Bertolino, E.; Lin, Y.C.; Laslo, P.; Cheng, J.X.; Murre, C.; Singh, H.; Glass, C.K. Simple Combinations of Lineage-Determining Transcription Factors Prime Cis-Regulatory Elements Required for Macrophage and B Cell Identities. Mol. Cell 2010, 38, 576-589. [CrossRef] [PubMed]

55. Thorvaldsdóttir, H.; Robinson, J.T.; Mesirov, J.P. Integrative Genomics Viewer (IGV): High-Performance Genomics Data Visualization and Exploration. Brief. Bioinform. 2013, 14, 178-192. [CrossRef] [PubMed]

56. Yu, G.; Wang, L.-G.; Han, Y.; He, Q.-Y. ClusterProfiler: An R Package for Comparing Biological Themes Among Gene Clusters. Omics J. Integr. Biol. 2012, 16, 284-287. [CrossRef] [PubMed]

57. Luo, C.; Lee, Q.Y.; Wapinski, O.; Castanon, R.; Nery, J.R.; Mall, M.; Kareta, M.S.; Cullen, S.M.; Goodell, M.A.; Chang, H.Y.; et al Global DNA Methylation Remodeling during Direct Reprogramming of Fibroblasts to Neurons. eLife 2019, 8, e40197. [CrossRef]

58. Feng, H.; Conneely, K.N.; Wu, H. A Bayesian Hierarchical Model to Detect Differentially Methylated Loci from Single Nucleotide Resolution Sequencing Data. Nucleic Acids Res. 2014, 42, e69. [CrossRef]

59. Hansen, K.D.; Langmead, B.; Irizarry, R.A. BSmooth: From Whole Genome Bisulfite Sequencing Reads to Differentially Methylated Regions. Genome Biol. 2012, 13, R83. [CrossRef]

60. Rizzardi, L.F.; Hickey, P.F.; Idrizi, A.; Tryggvadóttir, R.; Callahan, C.M.; Stephens, K.E.; Taverna, S.D.; Zhang, H.; Ramazanoglu, S.; Hansen, K.D.; et al. Human Brain Region-Specific Variably Methylated Regions Are Enriched for Heritability of Distinct Neuropsychiatric Traits. Genome Biol. 2021, 22, 116. [CrossRef]

61. McLean, C.Y.; Bristor, D.; Hiller, M.; Clarke, S.L.; Schaar, B.T.; Lowe, C.B.; Wenger, A.M.; Bejerano, G. GREAT Improves Functional Interpretation of Cis-Regulatory Regions. Nat. Biotechnol. 2010, 28, 495-501. [CrossRef] [PubMed]

62. Daley, T.; Smith, A.D. Predicting the Molecular Complexity of Sequencing Libraries. Nat. Methods 2013, 10, 325-327. [CrossRef] [PubMed]

63. Zhou, L.; Ng, H.K.; Drautz-Moses, D.I.; Schuster, S.C.; Beck, S.; Kim, C.; Chambers, J.C.; Loh, M. Systematic Evaluation of Library Preparation Methods and Sequencing Platforms for High-Throughput Whole Genome Bisulfite Sequencing. Sci. Rep. 2019, 9, 10383. [CrossRef] [PubMed] 
64. Ji, L.; Sasaki, T.; Sun, X.; Ma, P.; Lewis, Z.A.; Schmitz, R.J. Methylated DNA Is Over-Represented in Whole-Genome Bisulfite Sequencing Data. Front. Genet. 2014, 5, 341. [CrossRef]

65. Bird, A.P. CpG Islands as Gene Markers in the Vertebrate Nucleus. Trends Genet. 1987, 3, 342-347. [CrossRef]

66. Wienholz, B.L.; Kareta, M.S.; Moarefi, A.H.; Gordon, C.A.; Ginno, P.A.; Chédin, F. DNMT3L Modulates Significant and Distinct Flanking Sequence Preference for DNA Methylation by DNMT3A and DNMT3B In Vivo. PLoS Genet. 2010, 6, e1001106. [CrossRef]

67. Li, Y.; Zheng, H.; Wang, Q.; Zhou, C.; Wei, L.; Liu, X.; Zhang, W.; Zhang, Y.; Du, Z.; Wang, X.; et al. Genome-Wide Analyses Reveal a Role of Polycomb in Promoting Hypomethylation of DNA Methylation Valleys. Genome Biol. 2018, 19, 18. [CrossRef]

68. Straussman, R.; Nejman, D.; Roberts, D.; Steinfeld, I.; Blum, B.; Benvenisty, N.; Simon, I.; Yakhini, Z.; Cedar, H. Developmental Programming of CpG Island Methylation Profiles in the Human Genome. Nat. Struct. Mol. Biol. 2009, 16, 564-571. [CrossRef]

69. Meissner, A.; Mikkelsen, T.S.; Gu, H.; Wernig, M.; Hanna, J.; Sivachenko, A.; Zhang, X.; Bernstein, B.E.; Nusbaum, C.; Jaffe, D.B.; et al. Genome-Scale DNA Methylation Maps of Pluripotent and Differentiated Cells. Nature 2008, 454, 766-770. [CrossRef]

70. Dixon, G.; Pan, H.; Yang, D.; Rosen, B.P.; Jashari, T.; Verma, N.; Pulecio, J.; Caspi, I.; Lee, K.; Stransky, S.; et al. QSER1 Protects DNA Methylation Valleys from de Novo Methylation. Science 2021, 372, eabd0875. [CrossRef]

71. Feng, J.; Wilkinson, M.; Liu, X.; Purushothaman, I.; Ferguson, D.; Vialou, V.; Maze, I.; Shao, N.; Kennedy, P.; Koo, J.; et al. Chronic Cocaine-Regulated Epigenomic Changes in Mouse Nucleus Accumbens. Genome Biol. 2014, 15, R65. [CrossRef] [PubMed]

72. Phillips, J.E.; Corces, V.G. CTCF: Master Weaver of the Genome. Cell 2009, 137, 1194-1211. [CrossRef] [PubMed]

73. Chang, F.C.F.; Westenberger, A.; Dale, R.C.; Smith, M.; Pall, H.S.; Perez-Dueñas, B.; Grattan-Smith, P.; Ouvrier, R.A.; Mahant, N.; Hanna, B.C.; et al. Phenotypic Insights into ADCY5-Associated Disease. Mov. Disord. 2016, 31, 1033-1040. [CrossRef] [PubMed]

74. Kanehisa, M.; Goto, S. KEGG: Kyoto Encyclopedia of Genes and Genomes. Nucleic Acids Res. 2000, 28, 27-30. [CrossRef] [PubMed]

75. Urich, M.A.; Nery, J.R.; Lister, R.; Schmitz, R.J.; Ecker, J.R. MethylC-Seq Library Preparation for Base-Resolution Whole-Genome Bisulfite Sequencing. Nat. Protoc. 2015, 10, 475-483. [CrossRef]

76. Wang, Z.; Tang, B.; He, Y.; Jin, P. DNA Methylation Dynamics in Neurogenesis. Epigenomics 2016, 8, 401-414. [CrossRef]

77. Yao, B.; Christian, K.M.; He, C.; Jin, P.; Ming, G.; Song, H. Epigenetic Mechanisms in Neurogenesis. Nat. Rev. Neurosci. 2016, 17, 537-549. [CrossRef]

78. Hope, B.; Kosofsky, B.; Hyman, S.E.; Nestler, E.J. Regulation of Immediate Early Gene Expression and AP-1 Binding in the Rat Nucleus Accumbens by Chronic Cocaine. Proc. Natl. Acad. Sci. USA 1992, 89, 5764-5768. [CrossRef]

79. Nestler, E.J. $\Delta$ FosB: A Transcriptional Regulator of Stress and Antidepressant Responses. Eur. J. Pharmacol. 2015, 753, 66-72. [CrossRef]

80. Browne, C.J.; Godino, A.; Salery, M.; Nestler, E.J. Epigenetic Mechanisms of Opioid Addiction. Biol. Psychiatry 2020, 87, 22-33. [CrossRef]

81. Nestler, E.J. Transcriptional Mechanisms of Addiction: Role of FosB. Philos. Trans. R. Soc. B Biol. Sci. 2008, 363, 3245-3255. [CrossRef] [PubMed]

82. Bisagno, V.; Cadet, J.L. Expression of Immediate Early Genes in Brain Reward Circuitries: Differential Regulation by Psychostimulant and Opioid Drugs. Neurochem. Int. 2019, 124, 10-18. [CrossRef] [PubMed]

83. Imperio, C.G.; McFalls, A.J.; Hadad, N.; Blanco-Berdugo, L.; Masser, D.R.; Colechio, E.M.; Coffey, A.A.; Bixler, G.V.; Stanford, D.R.; Vrana, K.E.; et al. Exposure to Environmental Enrichment Attenuates Addiction-like Behavior and Alters Molecular Effects of Heroin Self-Administration in Rats. Neuropharmacology 2018, 139, 26-40. [CrossRef] [PubMed]

84. Sun, Z.; Xu, X.; He, J.; Murray, A.; Sun, M.; Wei, X.; Wang, X.; McCoig, E.; Xie, E.; Jiang, X.; et al. EGR1 Recruits TET1 to Shape the Brain Methylome during Development and upon Neuronal Activity. Nat. Commun. 2019, 10, 3892. [CrossRef] [PubMed]

85. Pulipparacharuvil, S.; Renthal, W.; Hale, C.F.; Taniguchi, M.; Xiao, G.; Kumar, A.; Russo, S.J.; Sikder, D.; Dewey, C.M.; Davis, M.M.; et al. Cocaine Regulates MEF2 to Control Synaptic and Behavioral Plasticity. Neuron 2008, 59, 621-633. [CrossRef]

86. Moore, J.E.; Purcaro, M.J.; Pratt, H.E.; Epstein, C.B.; Shoresh, N.; Adrian, J.; Kawli, T.; Davis, C.A.; Dobin, A.; Kaul, R.; et al. Expanded Encyclopaedias of DNA Elements in the Human and Mouse Genomes. Nature 2020, 583, 699-710. [CrossRef]

87. He, Y.; Ecker, J.R. Non-CG Methylation in the Human Genome. Annu. Rev. Genom. Hum. Genet. 2015, 16, 55-77. [CrossRef]

88. Guo, J.U.; Su, Y.; Shin, J.H.; Shin, J.; Li, H.; Xie, B.; Zhong, C.; Hu, S.; Le, T.; Fan, G.; et al. Distribution, Recognition and Regulation of Non-CpG Methylation in the Adult Mammalian Brain. Nat. Neurosci. 2013, 17, 215-222. [CrossRef]

89. Feng, S.; Zhong, Z.; Wang, M.; Jacobsen, S.E. Efficient and Accurate Determination of Genome-Wide DNA Methylation Patterns in Arabidopsis thaliana with Enzymatic Methyl Sequencing. Epigenetics Chromatin 2020, 13, 42. [CrossRef]

90. Han, Y.; Zheleznyakova, G.Y.; Marincevic-Zuniga, Y.; Kakhki, M.P.; Raine, A.; Needhamsen, M.; Jagodic, M. Comparison of EM-Seq and PBAT Methylome Library Methods for Low-Input DNA. Epigenetics 2021, 1-10. [CrossRef]

91. Liu, H.; Zhou, J.; Tian, W.; Luo, C.; Bartlett, A.; Aldridge, A.; Lucero, J.; Osteen, J.K.; Nery, J.R.; Chen, H.; et al. DNA Methylation Atlas of the Mouse Brain at Single-Cell Resolution. Nature 2021, 598, 120-128. [CrossRef]

92. Kriaucionis, S.; Heintz, N. The Nuclear DNA Base 5-Hydroxymethylcytosine Is Present in Purkinje Neurons and the Brain. Science 2009, 324, 929-930. [CrossRef] [PubMed]

93. Szulwach, K.E.; Li, X.; Li, Y.; Song, C.-X.; Wu, H.; Dai, Q.; Irier, H.; Upadhyay, A.K.; Gearing, M.; Levey, A.I.; et al. 5-HmCMediated Epigenetic Dynamics during Postnatal Neurodevelopment and Aging. Nat. Neurosci. 2011, 14, 1607-1616. [CrossRef] [PubMed] 
94. Schutsky, E.K.; DeNizio, J.E.; Hu, P.; Liu, M.Y.; Nabel, C.S.; Fabyanic, E.B.; Hwang, Y.; Bushman, F.D.; Wu, H.; Kohli, R.M. Nondestructive, Base-Resolution Sequencing of 5-Hydroxymethylcytosine Using a DNA Deaminase. Nat. Biotechnol. 2018, 36, 1083-1090. [CrossRef] [PubMed]

95. Ito, S.; Shen, L.; Dai, Q.; Wu, S.C.; Collins, L.B.; Swenberg, J.A.; He, C.; Zhang, Y. Tet Proteins Can Convert 5-Methylcytosine to 5-Formylcytosine and 5-Carboxylcytosine. Science 2011, 333, 1300-1303. [CrossRef]

96. Li, C.H.; Coffey, E.L.; Dall'Agnese, A.; Hannett, N.M.; Tang, X.; Henninger, J.E.; Platt, J.M.; Oksuz, O.; Zamudio, A.V.; Afeyan, L.K.; et al. MeCP2 Links Heterochromatin Condensates and Neurodevelopmental Disease. Nature 2020, 586, 440-444. [CrossRef]

97. Boxer, L.D.; Renthal, W.; Greben, A.W.; Whitwam, T.; Silberfeld, A.; Stroud, H.; Li, E.; Yang, M.G.; Kinde, B.; Griffith, E.C.; et al. MeCP2 Represses the Rate of Transcriptional Initiation of Highly Methylated Long Genes. Mol. Cell 2020, 77, 294-309.e9. [CrossRef]

98. Clemens, A.W.; Wu, D.Y.; Moore, J.R.; Christian, D.L.; Zhao, G.; Gabel, H.W. MeCP2 Represses Enhancers through Chromosome Topology-Associated DNA Methylation. Mol. Cell 2020, 77, 279-293.e8. [CrossRef]

99. Gabel, H.W.; Kinde, B.; Stroud, H.; Gilbert, C.S.; Harmin, D.A.; Kastan, N.R.; Hemberg, M.; Ebert, D.H.; Greenberg, M.E. Disruption of DNA-Methylation-Dependent Long Gene Repression in Rett Syndrome. Nature 2015, 522, 89-93. [CrossRef]

100. Chen, L.; Chen, K.; Lavery, L.A.; Baker, S.A.; Shaw, C.A.; Li, W.; Zoghbi, H.Y. MeCP2 Binds to Non-CG Methylated DNA as Neurons Mature, Influencing Transcription and the Timing of Onset for Rett Syndrome. Proc. Natl. Acad. Sci. USA 2015, 112, 5509-5514. [CrossRef]

101. Surmeier, D.J.; Carrillo-Reid, L.; Bargas, J. Dopaminergic Modulation of Striatal Neurons, Circuits, and Assemblies. Neuroscience 2011, 198, 3-18. [CrossRef] [PubMed]

102. Surmeier, D.J.; Song, W.-J.; Yan, Z. Coordinated Expression of Dopamine Receptors in Neostriatal Medium Spiny Neurons. J. Neurosci. 1996, 16, 6579-6591. [CrossRef] [PubMed]

103. Heiman, M.; Schaefer, A.; Gong, S.; Peterson, J.D.; Day, M.; Ramsey, K.E.; Suárez-Fariñas, M.; Schwarz, C.; Stephan, D.A.; Surmeier, D.J.; et al. A Translational Profiling Approach for the Molecular Characterization of CNS Cell Types. Cell 2008, 135, 738-748. [CrossRef] [PubMed]

104. Lobo, M.K.; Karsten, S.L.; Gray, M.; Geschwind, D.H.; Yang, X.W. FACS-Array Profiling of Striatal Projection Neuron Subtypes in Juvenile and Adult Mouse Brains. Nat. Neurosci. 2006, 9, 443-452. [CrossRef] [PubMed]

105. Lobo, M.K.; Covington, H.E.; Chaudhury, D.; Friedman, A.K.; Sun, H.S.; Damez-Werno, D.; Dietz, D.M.; Zaman, S.; Koo, J.W.; Kennedy, P.J.; et al. Cell Type-Specific Loss of BDNF Signaling Mimics Optogenetic Control of Cocaine Reward. Science 2010, 330, 385-390. [CrossRef]

106. Kravitz, A.V.; Tye, L.D.; Kreitzer, A.C. Distinct Roles for Direct and Indirect Pathway Striatal Neurons in Reinforcement. Nat. Neurosci. 2012, 15, 816-818. [CrossRef]

107. Hikida, T.; Kimura, K.; Wada, N.; Funabiki, K.; Nakanishi Shigetada, S. Distinct Roles of Synaptic Transmission in Direct and Indirect Striatal Pathways to Reward and Aversive Behavior. Neuron 2010, 66, 896-907. [CrossRef]

108. Rizzardi, L.F.; Hickey, P.F.; Rodriguez DiBlasi, V.; Tryggvadóttir, R.; Callahan, C.M.; Idrizi, A.; Hansen, K.D.; Feinberg, A.P. Neuronal Brain-Region-Specific DNA Methylation and Chromatin Accessibility Are Associated with Neuropsychiatric Trait Heritability. Nat. Neurosci. 2019, 22, 307-316. [CrossRef]

109. Feng, J.; Shao, N.; Szulwach, K.E.; Vialou, V.; Huynh, J.; Zhong, C.; Le, T.; Ferguson, D.; Cahill, M.E.; Li, Y.; et al. Role of Tet1 and 5-Hydroxymethylcytosine in Cocaine Action. Nat. Neurosci. 2015, 18, 536-544. [CrossRef]

110. LaPlant, Q.; Vialou, V.; Covington, H.E.; Dumitriu, D.; Feng, J.; Warren, B.L.; Maze, I.; Dietz, D.M.; Watts, E.L.; Iñiguez, S.D.; et al. Dnmt3a Regulates Emotional Behavior and Spine Plasticity in the Nucleus Accumbens. Nat. Neurosci. 2010, 13, 1137-1143. [CrossRef]

111. Handoko, L.; Xu, H.; Li, G.; Ngan, C.Y.; Chew, E.; Schnapp, M.; Lee, C.W.H.; Ye, C.; Ping, J.L.H.; Mulawadi, F.; et al. CTCFMediated Functional Chromatin Interactome in Pluripotent Cells. Nat. Genet. 2011, 43, 630-638. [CrossRef] [PubMed]

112. Torrano, V.; Chernukhin, I.; Docquier, F.; D'Arcy, V.; León, J.; Klenova, E.; Delgado, M.D. CTCF Regulates Growth and Erythroid Differentiation of Human Myeloid Leukemia Cells *. J. Biol. Chem. 2005, 280, 28152-28161. [CrossRef] [PubMed]

113. Narendra, V.; Rocha, P.P.; An, D.; Raviram, R.; Skok, J.A.; Mazzoni, E.O.; Reinberg, D. CTCF Establishes Discrete Functional Chromatin Domains at the Hox Clusters during Differentiation. Science 2015, 347, 1017-1021. [CrossRef] [PubMed]

114. Bell, A.C.; Felsenfeld, G. Methylation of a CTCF-Dependent Boundary Controls Imprinted Expression of the Igf2 Gene. Nature 2000, 405, 482-485. [CrossRef] [PubMed]

115. Hark, A.T.; Schoenherr, C.J.; Katz, D.J.; Ingram, R.S.; Levorse, J.M.; Tilghman, S.M. CTCF Mediates Methylation-Sensitive Enhancer-Blocking Activity at the H19/Igf2 Locus. Nature 2000, 405, 486-489. [CrossRef]

116. Kanduri, C.; Pant, V.; Loukinov, D.; Pugacheva, E.; Qi, C.F.; Wolffe, A.; Ohlsson, R.; Lobanenkov, V.V. Functional Association of CTCF with the Insulator Upstream of the H19 Gene Is Parent of Origin-Specific and Methylation-Sensitive. Curr. Biol. 2000, 10, 853-856. [CrossRef]

117. Hashimoto, H.; Wang, D.; Horton, J.R.; Zhang, X.; Corces, V.G.; Cheng, X. Structural Basis for the Versatile and MethylationDependent Binding of CTCF to DNA. Mol. Cell 2017, 66, 711-720.e3. [CrossRef]

118. Renda, M.; Baglivo, I.; Burgess-Beusse, B.; Esposito, S.; Fattorusso, R.; Felsenfeld, G.; Pedone, P.V. Critical DNA binding interactions of the insulator protein CTCF: A small number of zinc fingers mediate strong binding, and a single finger-DNA interaction controls binding at imprinted loci. J. Biol. Chem. 2007, 282, 33336-33345. [CrossRef] 
119. Zuo, Z.; Roy, B.; Chang, Y.K.; Granas, D.; Stormo, G.D. Measuring Quantitative Effects of Methylation on Transcription FactorDNA Binding Affinity. Sci. Adv. 2017, 3, eaao1799. [CrossRef]

120. Song, M.; Yang, X.; Ren, X.; Maliskova, L.; Li, B.; Jones, I.R.; Wang, C.; Jacob, F.; Wu, K.; Traglia, M.; et al. Mapping Cis-Regulatory Chromatin Contacts in Neural Cells Links Neuropsychiatric Disorder Risk Variants to Target Genes. Nat. Genet. 2019, 51, 1252-1262. [CrossRef]

121. Su, C.; Argenziano, M.; Lu, S.; Pippin, J.A.; Pahl, M.C.; Leonard, M.E.; Cousminer, D.L.; Johnson, M.E.; Lasconi, C.; Wells, A.D.; et al. 3D Promoter Architecture Re-Organization during IPSC-Derived Neuronal Cell Differentiation Implicates Target Genes for Neurodevelopmental Disorders. Prog. Neurobiol. 2021, 201, 102000. [CrossRef] [PubMed]

122. Chitaman, J.M.; Fraser, P.; Feng, J. Three-Dimensional Chromosome Architecture and Drug Addiction. Curr. Opin. Neurobiol. 2019, 59, 137-145. [CrossRef] [PubMed]

123. Vaillancourt, K.; Yang, J.; Chen, G.G.; Yerko, V.; Théroux, J.F.; Aouabed, Z.; Lopez, A.; Thibeault, K.C.; Calipari, E.S.; Labonté, B.; et al. Cocaine-Related DNA Methylation in Caudate Neurons Alters 3D Chromatin Structure of the IRXA Gene Cluster. Mol. Psychiatry 2020, 26, 3134-3151. [CrossRef] [PubMed]

124. Engmann, O.; Labonté, B.; Mitchell, A.; Bashtrykov, P.; Calipari, E.S.; Rosenbluh, C.; Loh, Y.H.E.; Walker, D.M.; Burek, D.; Hamilton, P.J.; et al. Cocaine-Induced Chromatin Modifications Associate with Increased Expression and Three-Dimensional Looping of Auts2. Biol. Psychiatry 2017, 82, 794-805. [CrossRef] [PubMed]

125. Markunas, C.A.; Semick, S.A.; Quach, B.C.; Tao, R.; Deep-Soboslay, A.; Carnes, M.U.; Bierut, L.J.; Hyde, T.M.; Kleinman, J.E.; Johnson, E.O.; et al. Genome-Wide DNA Methylation Differences in Nucleus Accumbens of Smokers vs. Nonsmokers. Neuropsychopharmacology 2020, 46, 554-560. [CrossRef] 